\title{
RESEARCH
}

Open Access

\section{Senescent accelerated prone 8 (SAMP8) mice as a model of age dependent neuroinflammation}

\author{
Andrés Fernández ${ }^{1 \dagger}$, Elena Quintana ${ }^{1 \dagger}$, Patricia Velasco ${ }^{1}$, Belén Moreno-Jimenez ${ }^{1}$, Belén de Andrés²,
} Maria Luisa Gaspar ${ }^{2}$, Isabel Liste ${ }^{1}$, Marçal Vilar ${ }^{3}$, Helena Mira ${ }^{3}$ and Eva Cano ${ }^{1 *}$ (D)

\begin{abstract}
Background: Aging and age-related diseases are strong risk factors for the development of neurodegenerative diseases. Neuroinflammation (NIF), as the brain's immune response, plays an important role in aged associated degeneration of central nervous system (CNS). There is a need for well characterized animal models that will allow the scientific community to understand and modulate this process.

Methods: We have analyzed aging-phenotypical and inflammatory changes of brain myeloid cells (bMyC) in a senescent accelerated prone aged (SAMP8) mouse model, and compared with their senescence resistant control mice (SAMR1). We have performed morphometric methods to evaluate the architecture of cellular prolongations and determined the appearance of $\mathrm{Iba} 1^{+}$clustered cells with aging. To analyze specific constant brain areas, we have performed stereology measurements of $\mid \mathrm{ba} 1^{+}$cells in the hippocampal formation. We have isolated bMyC from brain parenchyma (BP) and choroid plexus plus meningeal membranes $(\mathrm{m} / \mathrm{Ch})$, and analyzed their response to systemic lipopolysaccharide (LPS)-driven inflammation.

Results: Aged 10 months old SAMP8 mice present many of the hallmarks of aging-dependent neuroinflammation when compared with their SAMR1 control, i.e., increase of protein aggregates, presence of $\mathrm{Iba} 1^{+}$clusters, but not an increase in the number of $\mid \mathrm{ba} \mathrm{I}^{+}$cells. We have further observed an increase of main inflammatory mediator $\mathrm{IL}-1 \beta$, and an augment of border $\mathrm{MHCI}{ }^{+} \mid \mathrm{ba} 1^{+}$cells. Isolated $\mathrm{CD} 45^{+}$bMyC from brain parenchyma (BP) and choroid plexus plus meningeal membranes $(\mathrm{m} / \mathrm{Ch}$ ) have been analyzed, showing that there is not a significant increase of CD $45^{+}$cells from the periphery. Our data support that aged-driven pro-inflammatory cytokine interleukin 1 beta (IL-1 $\beta$ ) transcription is enhanced in CD45 BP cells. Furthermore, LPS-driven systemic inflammation produces inflammatory cytokines mainly in border bMyC, sensed to a lesser extent by the BP bMyC, showing that IL-1 $\beta$ expression is further augmented in aged SAMP8 compared to control SAMR1.

(Continued on next page)
\end{abstract}

\footnotetext{
* Correspondence: ecano@isciii.es

${ }^{\dagger}$ Andrés Fernández and Elena Quintana contributed equally to this work. 'Chronic Disease Programme, Neuroinflammation Unit, Instituto de Salud Carlos III, Carretera Majadahonda-Pozuelo, Km.2,2, Majadahonda, 28220 Madrid, Spain

Full list of author information is available at the end of the article
}

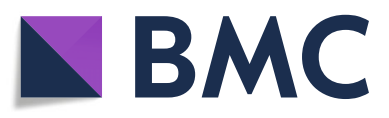

(c) The Author(s). 2021 Open Access This article is licensed under a Creative Commons Attribution 4.0 International License, which permits use, sharing, adaptation, distribution and reproduction in any medium or format, as long as you give appropriate credit to the original author(s) and the source, provide a link to the Creative Commons licence, and indicate if changes were made. The images or other third party material in this article are included in the article's Creative Commons licence, unless indicated otherwise in a credit line to the material. If material is not included in the article's Creative Commons licence and your intended use is not permitted by statutory regulation or exceeds the permitted use, you will need to obtain permission directly from the copyright holder. To view a copy of this licence, visit http://creativecommons.org/licenses/by/4.0/ The Creative Commons Public Domain Dedication waiver (http://creativecommons.org/publicdomain/zero/1.0/) applies to the data made available in this article, unless otherwise stated in a credit line to the data. 
(Continued from previous page)

Conclusion: Our data validate the SAMP8 model to study age-associated neuroinflammatory events, but careful controls for age and strain are required. These animals show morphological changes in their bMyC cell repertoires associated to age, corresponding to an increase in the production of pro-inflammatory cytokines such as IL-1 $\beta$, which predispose the brain to an enhanced inflammatory response after LPS-systemic challenge.

Keywords: Aging, Brain myeloid cells, Microglia, Inflammation, IL-1ß, SAMP8

\section{Background}

As life expectancy increases, age and age-related diseases have become a major health concern in western societies. Aging is the strongest risk factor for neurodegenerative diseases and while aging in itself is not considered a disease, results in important changes in brain tissue: significant increase in glial activation, complement factors and inflammatory mediators concomitant with brain atrophy $[1,2]$. Microarray and single-cell RNAseq studies of aged human and mouse brains have further extended these findings by showing that genes related to cellular stress and inflammation increase with age, while genes related to synaptic function/transport, growth factors, and trophic support become downregulated [3-6].

A link between aging, neuroinflammation, and promotion of neurodegenerative diseases such as Alzheimer disease (AD), Parkinson disease, or vascular-associated dementia has been proposed [7]. Neuroinflammation (NIF), defined as the brain's immune response, has been linked to age-associated neurodegeneration (reviewed in [8]). The central nervous system (CNS) was considered to be isolated and protected from immune responses, but it now appears that the blood-brain barrier (BBB) is not impermeable and that neuroinflammation occurs in the brain with similar features to inflammation in the periphery. In addition, a role for adaptive immune response in the CNS is now accepted (reviewed in [9, 10]). The main indicators of a primary neuroinflammatory response are phenotypic glial activation and de novo production of immune signaling molecules. Both, astrocytes and microglia, undergo cellular hypertrophy with increased expression of cell-surface immune modulatory proteins, including those of the major histocompatibility complex (MHC). These changes are accompanied by increased synthesis and release of pro-inflammatory cytokines and chemokines (reviewed in [11]). Although different types of cells have been involved in CNS inflammation, the main ones belong to the myeloid cell compartment. Brain myeloid cells (bMyC) mainly comprise microglia cells, and include perivascular, meningeal, and choroid plexus macrophages, peripheryderived monocytes, and brain dendritic cells (bDC), with a role in the establishment of neuroinflammation [12].
Parenchymal microglia, often referred as brain macrophages, are clearly implicated in the steady-state brain and in the response to different brain injuries. They have a myeloid origin; derive from embryonic yolk sac progenitors and are sustained thereafter by local progenitors [13-15]. One of the hallmarks of microglia cells is their age-dependent morphological changes. Microglia cells in the young healthy brain are cells with long and ramified prolongations [16, 17]. Aged microglia cells present ramified morphologies that are less branched, have shorter overall process lengths, and cover less dendritic "territory" than young microglia. Therefore, aged microglia presents a reduced "arborisation" $[18,19]$ and have characteristic accumulation in clusters, which might correspond to microglia responding to anomalous brain protein accumulation, stress related processes, or a direct effect of the aging process on microglia itself (reviewed in $[1,20,21]$ ). Furthermore, upon an inflammatory stimulus, these cells adopt an activated phenotype, which is characterized by morphological changes and cytokine synthesis, finally acquiring phagocytic capacity [22]. Morphologically, this activation is characterized by hypertrophy of cell body, widening of proximal processes and reduction of distal branches [23]. Therefore, the observation of changes in microglia cells in particular and bMyC in general, is a main characteristic of brain neuroinflammation.

Aging, as a progressive process associated to chronic low-grade inflammation and their neuroinflammatoryassociated events, has been linked to neurodegenerative diseases [24]. In rodent models of Alzheimer's disease (AD), chronic stress exacerbates neurodegeneration and cognitive impairments $[25,26]$, concomitant with increases of $\mathrm{A} \beta$ peptide accumulation and Tau protein phosphorylation (reviewed in [27]). In this context, the senescence accelerated mouse prone 8 (SAMP8) has been proposed as a neurodegeneration model to study late onset Alzheimer disease (LOAD) related to aging [20, 28-30]. This model presents many of the hallmarks found in neurodegenerative processes, as impairments in learning tasks, altered emotions, abnormality of the circadian rhythm [31], spongy degeneration [32], neuronal cell loss [33], and gliosis in the brain [34]. Notably, SAMP8 mice also show other characteristics seen in AD 
patients, such as memory deficits [35], increased $A \beta$ levels [21], impaired neurogenesis [36, 37], activation of microglia, and an unfavorable inflammatory microenvironment $[38,39]$. The neuroinflammatory state of SAMP8 model has been studied [40-42] but the specific changes that take place in the brain myeloid compartment of these animals remain to be fully explored.

The hallmark of neuroinflammatory response is phenotypic glial activation and the production of immune signaling molecules such as interleukin-1 $\beta$ (IL-1 $\beta$ ). IL-1 $\beta$ is involved in elaboration of acute neuroinflammatory events, and the main cellular source in the brain is microglia (reviewed in [43]). Aged microglia cells are skewed toward a phenotype characterized by increased pro-inflammatory cytokine release, such as IL-1 $\beta$, tumor necrosis factor- $\alpha$ (TNF- $\alpha$ ), and IL-6 [19, 44]. Furthermore, augmented expression of these pro-inflammatory cytokines has been observed in SAMP8 brain tissues [42], and an increase in inflammatory markers has been described in SAMP8 blood plasma. Also, persistent microglial pro-inflammatory activation exacerbates neuronal damages and amyloidosis already present in AD pathology [45].

In this context, it has been described that systemic inflammation has a role in the progression of chronic neurodegenerative diseases. A hallmark of aged microglia is the fact that they are primed by chronic inflammatory environment and, therefore, aged microglia responds more vigorously to a given systemic inflammatory stimuli. This phenomenon was introduced as microglia priming [19, 46, 47]; reviewed in [48]. Innate immunity activates defensive mechanisms within minutes of microbial invasion through pattern recognition receptors (PRRs) such as Toll-like receptors (TLRs). TLRs have been involved in microglia responses to different insults, such as lipopolysaccharides (LPS), components of the outer membrane of Gram-negative bacteria or very different brain insults such as prion related peptides $[49,50]$.

LPS are responsible for the induction of inflammatory conditions, and LPS systemic administration has been widely used to test immune system activation and their role in neurodegeneration [51]. Although high LPS doses can lead to pathological reactions such as the induction of septic shock, low doses of circulating LPS are associated with chronic disease characterized by persistent low-grade inflammation [52]. This inflammatory response involves activation of PRRs and subsequent production of many pro-inflammatory cytokines such as IL-1 $\beta$, TNF- $\alpha$, or IL- 6 . In the present study, we have asked if isolated bMyC from aged senescent SAMP8 recapitulate this enhanced response.

In this work, we have analyzed the number and function of bMyC in the senescence SAMP8 model compared to the resistant control strain SAMR1. We have analyzed the morphology and distribution of hippocampal macrophages/microglia $\left(\mathrm{Iba}^{+}{ }^{+}\right.$) cells by immunohistochemistry. We have quantified the number of hippocampus Iba $1^{+}$using stereology methods comparing young (2 months) with aged (10 months) animals from both strains, isolated and analyzed the number of CD $45^{+}$ cells by flow cytometry studies. Finally, we have studied the expression of pro-inflammatory cytokines produced by isolated bMyC from the two main areas in which they are abundant: the BP and brain areas in contact with the periphery, $\mathrm{m} / \mathrm{Ch}$. We have further evaluated the response to low doses of inflammatory challenge on isolated cells from BP and $\mathrm{m} / \mathrm{Ch}$, and we have uncovered different activation kinetics of cells from both brains localizations.

\section{Methods \\ Mice}

Adult (2 to 10 months old) SAMP8 and SAMR1 mice were bred and maintained in the animal facilities at the Centro Nacional de Microbiología, Instituto de Salud Carlos III (CNM-ISCIII, Madrid, Spain). Male double transgenic APP/PS1 mice (10 months old), a cross between Tg2576 (overexpressing human APP695) and mutant PS1 (M146L), were kindly provided by Eva Carro [53]. All animal experiments were approved by the Institutional Review Board at the ISCIII and carried out in strict accordance with EU and National Animal Care guidelines. Protocols were approved by Consejería de Medio Ambiente Comunidad de Madrid (PROEX 17914).

\section{Tissue processing}

For confocal preparations, mice were deeply anesthetized by intraperitoneal (ip) injection of a mixture of ketamine and xylazine and transcardially perfused with 25-30 mL of saline solution for $5 \mathrm{~min}$, followed by 10 min incubation with $4 \%$ paraformaldehyde (PFA, Sigma), $\mathrm{pH}$ 7.4, in $0.1 \mathrm{M}$ phosphate buffer (PB, Sigma). After perfusion with the fixative, brains were dissected out and post fixed with $4 \%$ PFA for $18-20 \mathrm{~h}$ at $4^{\circ} \mathrm{C}$. After fixation, brains were rinsed in $0.1 \mathrm{M} \mathrm{PB}$ and placed in $15 \%$ sucrose at $4^{\circ} \mathrm{C}$ until they sank, and then in $30 \%$ sucrose in $\mathrm{PB}$ at $4^{\circ} \mathrm{C}$ for $72 \mathrm{~h}$. Finally, brains were embedded in tissue freezing medium (Tissue-Tek O.C. ${ }^{\mathrm{TM}}$, Sakura), by submerging them in increasing concentrations of OCT, frozen immediately in dry-ice-cooled 2 -methylbutane (Sigma), and stored at $-80^{\circ} \mathrm{C}$. Coronal sections $(30 \mu \mathrm{m})$ were cut using a CM1950 cryostat (Leica Microsystems). Brain sections were collected sequentially in 10 slides. Six sections per slide generate antero-posterior reconstructions of the hippocampus 
conformed by 1 section every $300 \mu \mathrm{m}$ of hippocampal structure. Slides were stored at $-20^{\circ} \mathrm{C}$ until use.

\section{Periodic acid-Schiff (PAS) stain}

Frozen brains embedded in OCT were cut into $30-\mu \mathrm{m}$ thick sections as described before. Sections of the central zone of the hippocampus were selected according to mouse brain atlas [54]. Brain sections were dried at RT for $24 \mathrm{~h}$, and sequentially submerged in absolute ethanol $(\mathrm{EtOH})(2 \mathrm{x})$, in $96 \% \mathrm{EtOH}(2 \mathrm{x})$, and in $70 \% \mathrm{EtOH}(1 \mathrm{x})$. Finally, samples were hydrated in deionized water and immerse in $0.5 \%$ periodic acid for $5 \mathrm{~min}$ at room temperature $\left(18-26^{\circ} \mathrm{C}\right)$. Slides were rinsed in several changes of distilled water and immersed in Schiff's Reagent (Sigma) for 15 to $20 \mathrm{~min}$ at $4{ }^{\circ} \mathrm{C}$. Slides were rinsed in running tap water for $5 \mathrm{~min}$. For nuclei staining, slides were counterstained in hematoxylin solution, Gill No. 3 (Thermo Fisher), for $10 \mathrm{~min}$, rinsed with alcohol acid $(0.5 \% \mathrm{HCl}$ in $\mathrm{EtOH})$ three times and a final rinsed in tap water. Finally, slices were dehydrated, cleared, and mounted in DPX (Sigma) media.

\section{Immunohistochemistry}

Immunohistochemistry analyses were performed on frozen brain sections by standard indirect staining as in [55]. Antibodies were diluted in $0.1 \mathrm{M} \mathrm{PB}$ containing $1 \%$ fetal bovine serum (FBS, Hyclone), 0.06\% Triton-X100 (Sigma), and $150 \mathrm{mM}$ glycine (Merck). Rabbit anti-Iba1 (1:100, Wako) was used to detect expression of bMyC; rat anti-mouse I-A/I-E (1:100, clone 2G9, B.D. Pharmingen) was used to detect antigen-presenting cells; mouse anti-phospho-Ser 139-Histone H2AX (clon JBW301, Millipore) was used to analyze DNA damage. Alexa fluor 488-labeled donkey anti-rabbit, -rat, -mouse, and Cy3labeled donkey anti-rat antibodies (Jackson) were used as secondary antibodies. After staining, all sections and cells were mounted and preserved with 50\% Mowiol (Polysciences), 2.5\% DABCO (Sigma).

\section{Confocal microscopy and analysis}

Images were acquired on a Leica Spectral SP5 confocal microscope. Brain maps were imaged using a $\times 20$ immersion objective and a 1.7 digital zoom. Tissue images are tiles of 2-4 $\mu \mathrm{m}$ z-stacks and cell images are single $1-2 \mu \mathrm{m} z$ stacks both captured with $40 \mathrm{x}$ and $63 \mathrm{x}$ oil objectives. Images are presented as average projections of z-stacks and keeping parameters constant. Exceptions are mentioned in figure legends. Negative control slides stained with primary antibody were used to identify potential nonspecific, background fluorescence. Acquired z-stacks were background-subtracted with the Leica LAS AF 2.6.3 software and secondary processed and analyzed using Adobe Photoshop CS3 (Adobe Systems) and Image (National Institute of
Health, http://rsb.info.nih.gov/ij) for ROI quantification and cell counting.

\section{Stereology and statistical analysis}

Stereology was performed by the analysis of 6 coronal sections, $30 \mu \mathrm{m}$ each, and separated $300 \mu \mathrm{m}$ one from each other. Sampling started at first appearance of the infrapyramidal blade of the dentate gyrus (DG). Anteroposterior Bregma coordinates of all 6 sections correspond approximately to $-1.2 \mathrm{~mm}$ to $-2.7 \mathrm{~mm}$ [54]. Every quantification was normalized with the DG area of every section.

For statistical analysis, the GraphPad Prism software (Version 8.4.1; GraphPad Software, San Diego, CA 92108) was used after testing the normality of the data distributions with the Kolmogorov-Smirnov and D'Agostino-Pearson tests. Analysis of variance (ANOVA) was used for statistical analysis of differences between ages of the same strain. Post-hoc comparisons were performed using the Tukey test, and the Bonferroni correction was applied. Data were also analyzed by unpaired two tailed Student's $t$ test for comparisons of both SAMR1 and SAMP8 strains of the same age. Data are presented as mean \pm standard error of the mean (SEM) and $n$ indicates the number of independent mice used per strain and age. A $p$ value of $<0.05$ was considered as statistically significant.

\section{Image analysis for morphometric parameters calculation}

Three-dimensional (3D) reconstruction of individual microglial cells z-stack confocal images of around $30 \mu \mathrm{m}$ thickness at intervals of $1 \mu \mathrm{m}$ were taken at specified areas of SAMR1 and SAMP8 brains of different age. 3D images were obtained by using the plugin $3 \mathrm{D}$ viewer of the FIJI software (freely downloadable from http://fiji.sc/ Fiji). To analyze spatial coverage of microglia, we used modified methods as described in [18]. Briefly, brain sections from these mice were stained with Iba1, hippocampal formation (Hpp) together with areas within: strata pyramidale (sp) and oriens (so) were imaged with confocal microscopy as before. Then, gray-level maximum $\mathrm{z}$ projection images were set to eliminate background based on intensity threshold and converted to binary images, processed with the "skeletonize" option in the FIJI software, and further analyzed with a modified Sholl's analysis adapted for microglia as in $[18,56]$. A representative heat-map image was generated based on 8-bit z-projection image using the 3D Surface Plot plugin bundled in the FIJI software. For morphometric parameter calculation, after tracing an individual microglial cell, we calculated the number of intersections between microglial processes and concentric circles originated from the center of individual cell by using the Sholl's analysis plug-in (Ghosh Lab, UCSD, San Diego, CA, 
USA) bundled in FIJI. This was used to analyze the number of intersections in circles with a radius between $5 \mu \mathrm{m}$ (starting radius) as minimal distance corresponding to the soma of the cell and the final radio which includes the longest microglia branch (ending radius). We analyzed at least 25 individual $\mathrm{Iba}^{+}$cells from at least three individual animals. We present the data by using polynomial regression and defining three parameters: critical value of the circle radius (which defines the place of a possible circle intersecting maximum number of dendrites); the maximum number of ramification intersections with the circles (counted for consecutive circles placed starting at the cell body to the border of the arborisation and the mean value of the fitted polynomial function (which describes an average property concerning number of branches of ramification tree over the whole region occupied by the ramification arbor). For that purpose, we also used the Sholl regression coefficient as well as the Schoenen ramification index similar to that described previously $[57,58]$.

\section{LPS administration to mice}

To assess the response of brain myeloid cells to peripheral immune stimulation, mice received a single intraperitoneal injection (i.p.) of 0.5 to $1 \mathrm{mg} / \mathrm{kg}$ LPS from E. coli, \#0111:B4; L4391-IMG (Sigma). The LPS powder was dissolved in $0.9 \%$ endotoxin-free sterile saline at a concentration of $10 \mathrm{mg} / \mathrm{mL}$. Mice injected with sterile saline as vehicle were used as control. Brains were collected and cell preparations and mRNA expression analyses were as follow.

\section{Cell preparation}

Two and 10 months old SAMP8 and SAMR1 mice (or otherwise specified) were sacrificed, and intracardiac perfusion was performed using phosphate buffered saline (PBS) with observed blanching of the spleen during 5 min at a speed of $5 \mathrm{~mL} / \mathrm{min}$. Complete brains were dissected and for most experiments, meningeal (piamater) membranes and choroid plexus $(\mathrm{m} / \mathrm{Ch})$ were carefully removed with fine tweezers. Brain tissue was finely minced into small pieces and treated with a specific protease mix depending on the tissue. For brain without $\mathrm{m} / \mathrm{Ch}$, cells were prepared as in [55]. Brain, without the $\mathrm{m} / \mathrm{Ch}$ and cerebellum, was digested in $5 \mathrm{~mL}$ of enzyme solution 20 units $/ \mathrm{mL}$ papain (Worthington) and 0.025 units/mL DNase (Sigma) in buffer containing $116 \mathrm{mM} \mathrm{NaCl}, 5.4 \mathrm{mM} \mathrm{KCl}, 26 \mathrm{mM} \mathrm{NaHCO}, 1 \mathrm{mM}$ $\mathrm{NaH}_{2} \mathrm{PO}_{4}, 1.5 \mathrm{mM} \mathrm{CaCl}, 1 \mathrm{mM} \mathrm{MgSO} 4,0.5 \mathrm{mM}$ EDTA, $25 \mathrm{mM}$ glucose, and $1 \mathrm{mM}$ L-cysteine, $\mathrm{pH} 7.5$ for $30 \mathrm{~min}$ at room temperature (RT) with agitation. The brain homogenate was washed and filtered once through a 70- $\mu \mathrm{M}$ filter to remove undigested fragments and then washed twice more, followed by centrifugation at $300 \times g$ for $7 \mathrm{~min}$. Cells were resuspended in 30\% Percoll (GE Lifesciences) under $5 \mathrm{~mL}$ Hanks' Balanced Salt Solution (HBSS) and centrifuged at $300 \times g$ for $20 \mathrm{~min}$ at RT with slow acceleration and no brake. Pellets were collected and washed with ice-cold PBS containing $2 \%$ (vol/vol) FBS (spin $300 \times g$, $7 \mathrm{~min}$ ). All subsequent washes were performed in this buffer. This preparation contains microglia/macrophages from brain as in [59], with the exception of those from meningeal membrane, choroid plexus, and cerebellum; we refer to this cell preparation as brain myeloid cells (bMyC) from BP. For m/Ch cell isolates, meningeal membranes plus choroid plexus were collected in an Eppendorf containing $1 \mathrm{~mL}$ PBS. Tissue was treated with $2.5 \mathrm{mg} / \mathrm{mL}$ Pronase (Roche) plus 0.025 units/mL DNase (Sigma) in PBS during $30 \mathrm{~min}$ at $37^{\circ} \mathrm{C}$ in a bath with mixing. This was followed by homogenization with gentle trituration using glass pipettes. $\mathrm{m} / \mathrm{Ch}$ homogenates were filtered and treated as above. All subsequent steps were performed at $4^{\circ} \mathrm{C}$ in PBS, 2\% FBS.

\section{$\mathrm{CD}^{+} 5^{+}$cell purification}

After enrichment on Percoll gradient, brain isolated cells were purified using MACS LS columns from Miltenyi Biotec, following manufacturer's instructions. Cells were washed in PBS $2 \%$ FBS and resuspended in $180 \mu \mathrm{L}$ of PBS $0.5 \%$ BSA $2 \mathrm{mM}$ EDTA per brain sample, using MACS solutions. All steps were carried out on this buffer. CD45 mouse microbeads $(20 \mu \mathrm{L})$ were added to the cells and incubated on ice during $15 \mathrm{~min}$. Five milliliters were then added and cell suspension was centrifuged $10 \mathrm{~min}$ at $300 \times g$. Supernatant was discarded and cells were resuspended in $5 \mathrm{~mL}$ and applied to the column, attached to MACS Separator and previously equilibrated with same buffer. Before passing the preparation through the column, cell preparation was filtered with $70-\mu \mathrm{m}$ filter. The column was washed with $10 \mathrm{~mL}$ MACS solution and cells were extracted from column in $5 \mathrm{~mL}$ according to Miltenyi protocol. Cells were centrifuged again and resuspended in $1 \mathrm{~mL}$ of $2 \% \mathrm{FBS}$ in PBS, counted in a Neubauer chamber and prepared for following applications.

\section{Flow cytometry}

Single-cell suspensions were prepared as above and resuspended in staining buffer ( $2 \%$ FBS in PBS). Nonspecific binding to $\mathrm{Fcy}$ receptors was blocked with $10 \mu \mathrm{g} / \mathrm{mL}$ of $2.4 \mathrm{G} 2 \mathrm{mAb}$ (Fc block, BD Biosciences). Staining was performed following standard protocols. Fluorochrome-labeled antibodies specific for mouse CD45, CD11b, P2RY12, and CD49d were from BD Biosciences or Biolegend. Cells were analyzed on a LRS Fortessa X-20 (BD Biosciences) cytometer, using the FlowJo v6.3.4 (TreeStar) and DIVA v8.0 software packages (BD 
Biosciences). The gating strategy used to exclude dead cells and doublets as in Additional Fig 2s.

\section{RNA isolation and real-time PCR}

Total RNA was isolated with TriPure Isolation Reagent (Roche). Two micrograms of RNA were reverse transcribed using MMLV Transcriptase Reverse (Invitrogen), following the manufacturer's instructions, except for using, $600 \mathrm{ng}$ of random primers and 4 units of RNase OUT (Invitrogen).

Relative amounts of cDNA were analyzed by quantitative real-time PCR (qRT-PCR) using the FAST SYBRgreen system and 7500 thermal cycler (Applied Biosystems). Ten nanograms of cDNA were analyzed in $15 \mu \mathrm{L}$ reaction volume that includes $7.5 \mu \mathrm{L}$ of $2 \mathrm{x}$ Reaction Mix, $0.5 \mu \mathrm{L}$ of $10 \mu \mathrm{M}$ of each primer. Thermal protocol consisted of a denaturation step at $95^{\circ} \mathrm{C}$ for $20 \mathrm{~s}$, then 40 cycles of $3 \mathrm{~s}$ at $95^{\circ} \mathrm{C}$ and $30 \mathrm{~s}$ at $60^{\circ} \mathrm{C}$, followed by a final step of $15 \mathrm{~s}$ at $95^{\circ} \mathrm{C}$ and $1 \mathrm{~min}$ at $60^{\circ} \mathrm{C}$. Finally, a melting curve was performed from 60 to $95^{\circ} \mathrm{C}$ with $1 \%$ temperature ramp rate. Mouse 36b4 expression was used as an internal control to normalize for variations in input RNA. The amount of target mRNA in samples was estimated following the $2^{-\Delta \Delta C T}$ relative quantification method [60].

Used primers are as follows:

\begin{tabular}{ll}
\hline 36b4: & Forward: AGATGCAGCAGATCCGCAT \\
& Reverse: GTTCTTGCCCATCAGCACC \\
II-13: & Forward: CAACCAACAAGTGATATTCTCCATG \\
& Reverse: GATCCACACTCTCCAGCTGCA \\
Tnf-a: & Forward: TGGAACTGGCAGAAGAG \\
& Reverse: CCATAGAACTGATGAGAGG \\
II-6: & Forward: GAGGATACCACTCCCAACAGACC \\
& Reverse: AAGTGCATCATCGTTGTCATACA \\
Ccl2: & Forward: CGGAACCAAATGAGATCAGAACCTAC \\
& Reverse: GCTTCAGATTTACGGGTCAACTCAC \\
Aif-1: & Forward: GGGAAAGTCAGCCAGTCCT \\
& Reverse: GCATCACTTCCACATCAGCTT \\
Cx3cr1: & Forward: TCAGCATCGACCGGTACCT \\
& Reverse: CTGCACTGTCCGGTTGTCA \\
\hline
\end{tabular}

\section{Results}

Hippocampal PAS positive granules increase in aged SAMP8

As it has been previously stated, the presence of granular accumulation is a hallmark of the neurodegenerative associated process in human brain [61], and aged animals [62]. These accumulations are often referred to as PAS positive granules, although their nature in different mouse strains is still under discussion. PAS positive granules have been observed in the hippocampus and entorhinal cortex of a variety of different species and associated to aging in SAMP8 animal model (reviewed in [63]). To localize a valid area of the brain in which neurodegenerative-associated processes are taking place, we analyzed 2 months and aged 10 months old animals from the SAMP8 strain. We also evaluated $10 \mathrm{~m}$ old SAMR1 $\mathrm{Hpp}$ as non-senescent control, and aged $10 \mathrm{~m}$ transgenic APP-PS1 Hpp as neurodegeneration-associated control. PAS positive granules were observed in hippocampus ( $\mathrm{Hpp}$ ) mainly in the CA1 region as described [64] and shown in Fig. 1a. The hippocampus (Hpp) in this study refers to the dentate gyrus (DG) and the cornu ammonis 1 (CA1) area (scheme Fig. 1b, panel i). As shown in Fig. 1b, panel ii, a very clear increase of PAS positive granules was observed in Hpp from $10 \mathrm{~m}$ old SAMP8 brains, compared to $10 \mathrm{~m}$ SAMR1, in numbers that were comparable with those obtained in 10 months old APP-PS1 transgenic animals (Fig. 1b). The presence of these aged-associated protein accumulations indicate that brain $\mathrm{Hpp}$ is a suitable area to study the neurodegeneration associated neuroinflammation derived events that take place.

\section{$\mathrm{lba} 1^{+}$cells from aged SAMP8 mice present clear morphological changes}

Microglial morphology is altered in the cortex of aged human [2] and old mice [18]. Therefore, we aimed to study the complexity of microglia processes with age in SAMP8. We took serial z-stack and traced the backbone of cells throughout them with the FIJI software, as specified in material and methods. We performed Sholl analysis as a morphometric method that evaluates the architecture of cellular prolongations; these analyses draw a series of concentric circles around the cell soma, and consist of a mathematical method that gives a measure of the prolongation arborisation that can be used to study microglia ramifications $[65,66]$. We obtained the number of primary ramifications as the number of extension originated in the cellular body or soma, and the Schoenen ramification index (SRI), described as the ratio between the maximum number of the intersections of microglia ramifications with the circles and the number of the primary ramifications. Our analyses show that 2 months old SAMP8 Hpp presented a lesser arborisation index than their 2 months old Hpp SAMR1 controls. In contrast, 10 months old SAMP8 $\mathrm{Hpp} \mathrm{Iba1}^{+}$cells have similar number of primary ramifications compared to their 10 months SAMR1 counterparts, although significant changes in their ramification index were observed (Fig. 2). Therefore, we conclude that $\mathrm{Iba}^{+}$cells in aged SAMP8 animals present morphological changes similar to those described in normal aging $[18,67]$. Furthermore, aged SAMP8 $\mathrm{Iba}^{+}$cells 


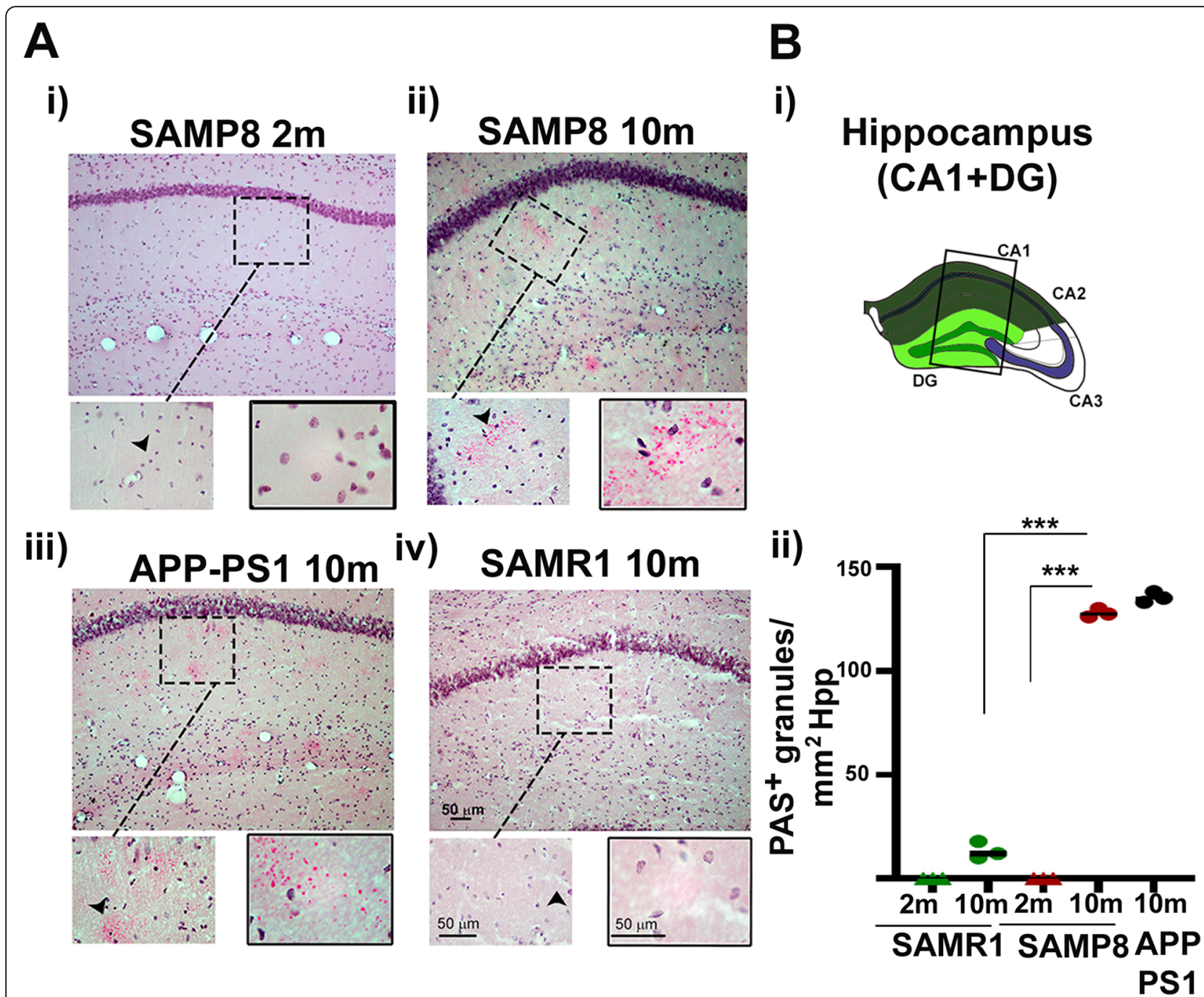

Fig. 1 Analysis of PAS accumulations in SAM mice associated with aging and neurodegeneration. (a) Representative captures of hippocampal regions in SAMR1 and SAMP8 mice of 2 and 10 months $(\mathrm{m})$ and $10 \mathrm{~m}$ old APP-PS1 mice, showing PAS-positive granules. Brain sections were stained by Schiff's reagent (red-pink) and nuclei with hematoxylin (blue-brown). Images of coronal sections of cryostat (30 $\mu \mathrm{m}$ thick) were obtained with a $\times 20$ objective (upper images), $\times 40$ and $\times 100$ (from left to right for magnified pictures), with a Nikon Eclipse 50i H550S light microscope and processed with the help of the NIS elements of software and ImageJ. (b) (i) Schematic representation of the regions analyzed. (ii) Quantification of PAS positive accumulates/ $\mathrm{mm}^{2}$. SAMR1 is shown in green, SAMP8 in red, and APP PS1 in black. Two months data are represented with triangles and 10 months with circles. ${ }^{* *} p<0.01$ and ${ }^{* * *} p<0.001$ with respect to the PAS/mm ${ }^{2}$ accumulations $(n=3$ to 5 males). Scale bars are included in the images

occupied smaller territories, and they displayed more irregular processes than control animals.

\section{Clustered $\mathrm{Iba}^{+}$cells in aged SAMP8 do not express} specific markers for DNA damage $(\mathrm{\gamma H} 2 \mathrm{AX})$ nor activation related marker such as $\mathrm{MHCII}$

Another age-dependent microglia morphological change is the appearance of dystrophic microglia and cellular clusters $[68,69]$. Therefore, we analyzed the number of very apparent $\mathrm{Iba}^{+}$clusters (defined as multinucleated or joined cells) in SAMP8 and SAMR1 brains at different age. We chose two representative brain areas: the stratum oriens in the Hpp and the thalamus. Iba $1^{+}$ clusters were hardly present in $2 \mathrm{~m}$ and $10 \mathrm{~m}$ SAMR1, whereas small clusters of 2 to 3 nuclei were observed in 2 months and 10 months old SAMP8 Hpp (Fig. 3a, panel $i$ and quantified in panel ii). The number of these clustered cells was higher in SAMP8 Hpp versus SAMR1 Hpp independently of age (Fig. 3a, panel ii). When the thalamus region was visualized in these animals, the presence of big $\mathrm{Ibal}^{+}$clusters was prominent in 10 months old SAMP8 brains (Fig. 3a, panel iii), although we found rare small clusters in thalamic 10 months SAMR1 brains regions (see insert and Fig. 3a, panel iv). 


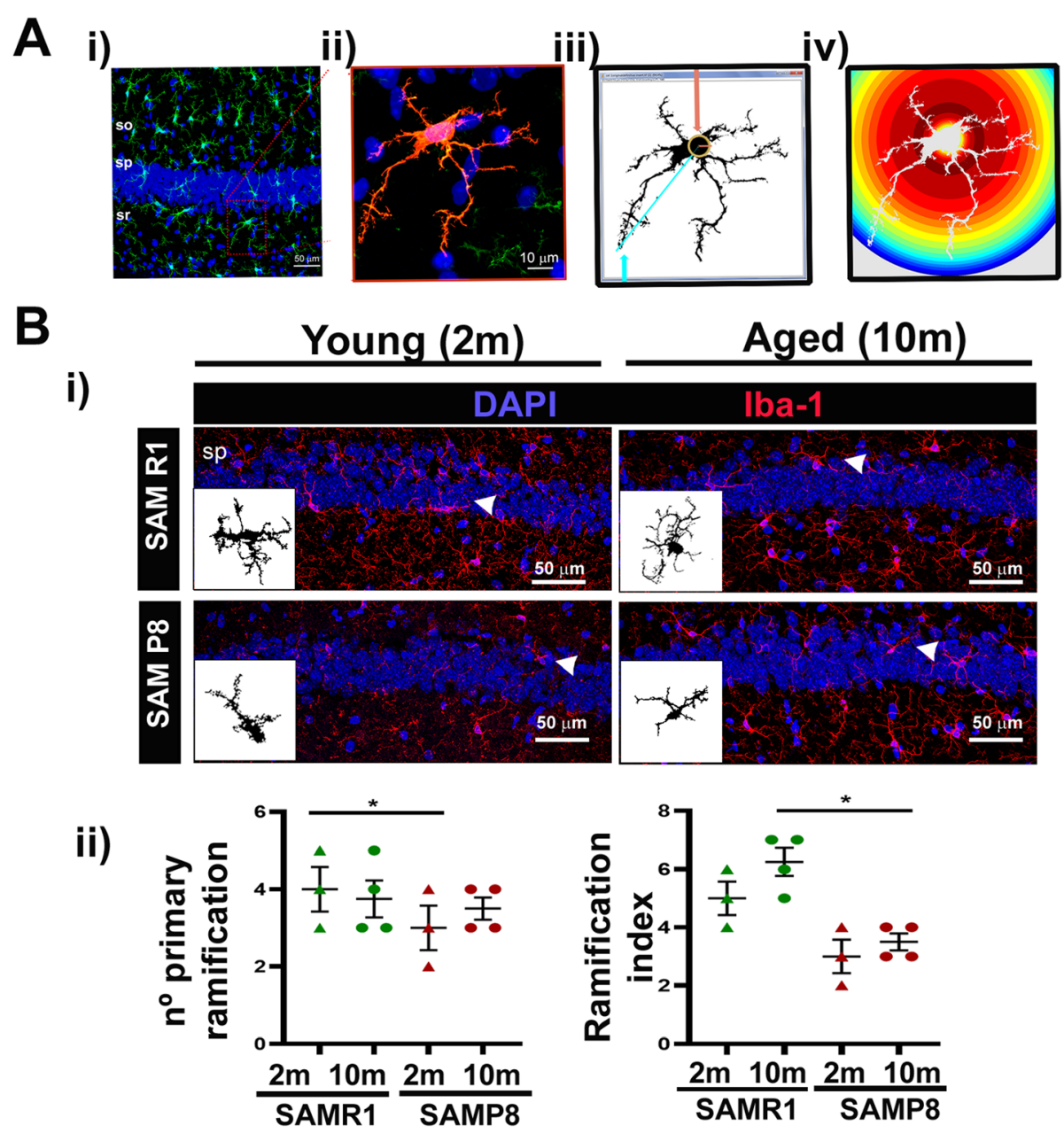

Fig. 2 Morphology analysis by Sholl analysis. (a) (i) Representative images of hippocampus $\mid \mathrm{ba} 1^{+}$(green) regions used for analysis. so, stratum oriens; sp, stratum pyramidale; sr, stratum radiale. (ii) Detailed capture of cell morphology of an $\mid \mathrm{bba} \mathrm{l}^{+}$cell (red) maximum projection. (iii) Binary image of the maximum projection of the detailed image. (iv) Cartoon showing the radius of the longest extension that corresponds to the radius of the largest concentric circle and furthest from the soma (ending radius or maximum radius) and the radius that would cover the soma (starting radius or initial radius). (b) (i) Representative images of brain maps from 2 months and 10 months SAM Hpp areas using a $\times 40$ objective and $\times 1.7$ digital zoom. Insets show $\times 63$ detailed images of iba $1^{+}$positive binary images for cell morphology. Nuclei are stained with DAPI (blue); brain microglia/macrophages are stained with Iba-1 (red). Scale bars are included in the images. (ii) Sholl analysis results, number of primary branches and branch index from Ibal ${ }^{+}$cells from 2 (triangles) and 10 months (circles) old SAM mice Hpp area $(n=3$ male). SAMR1 is shown in green and SAMP8 in red. Images were obtained with a Leica SP5 TCS inverted fluorescence confocal microscope, from $30 \mu \mathrm{m}$ thick cryostat sections

The origin of these cellular clusters is unknown, and we hypothesize that might be due to cellular aging and associated DNA damage. DNA damage, either endogenous or exogenous, forms double stranded breaks (DSBs) a phenomena that is followed by the phosphorylation of the histone gamma $\mathrm{H} 2 \mathrm{AX}\left(\gamma \mathrm{H} 2 \mathrm{AX}^{+}\right)$[70]. Furthermore, expression of $\gamma \mathrm{H}_{2} \mathrm{AX}^{+}$cells has been used as a cellular senescence marker [71]. We evaluated the number of $\gamma \mathrm{H}_{2} \mathrm{AX}^{+}$cells in 10 months old SAMP8 animals, focusing on $\mathrm{Iba}^{+}$cells. We found $\gamma \mathrm{H} 2 \mathrm{AX}^{+}$cells in aged 10 months SAMP8 brains, but most of these cells did not express the Iba1 marker, in accordance to previously reported data [72]. The number of double positive $\gamma \mathrm{H} 2 \mathrm{AX}^{+} \mathrm{Iba1}^{+}$cells in the thalamic regions, where $\mathrm{Iba}^{+}$ clusters were most noticed, was very low $(<$ of $0.1 \pm$ $0.01 \%)$. These results indicate that clustered $\mathrm{Iba}^{+}{ }^{+}$cells do not specifically present associated DNA damage events, and may be functional microglia. $\gamma \mathrm{H} 2 \mathrm{AX}^{+}$cells that are not microglia are possibly astrocytes and neurons, which have previously shown to be positive in neurodegenerative brains [72-75].

Microglia cells represent the main antigen-presenting cells inside the BP during neurodegeneration. While expression of MHCII is low under homeostatic conditions in the brain, it can be rapidly upregulated on bMyC and it is used as a marker of their activation [76]. We asked 


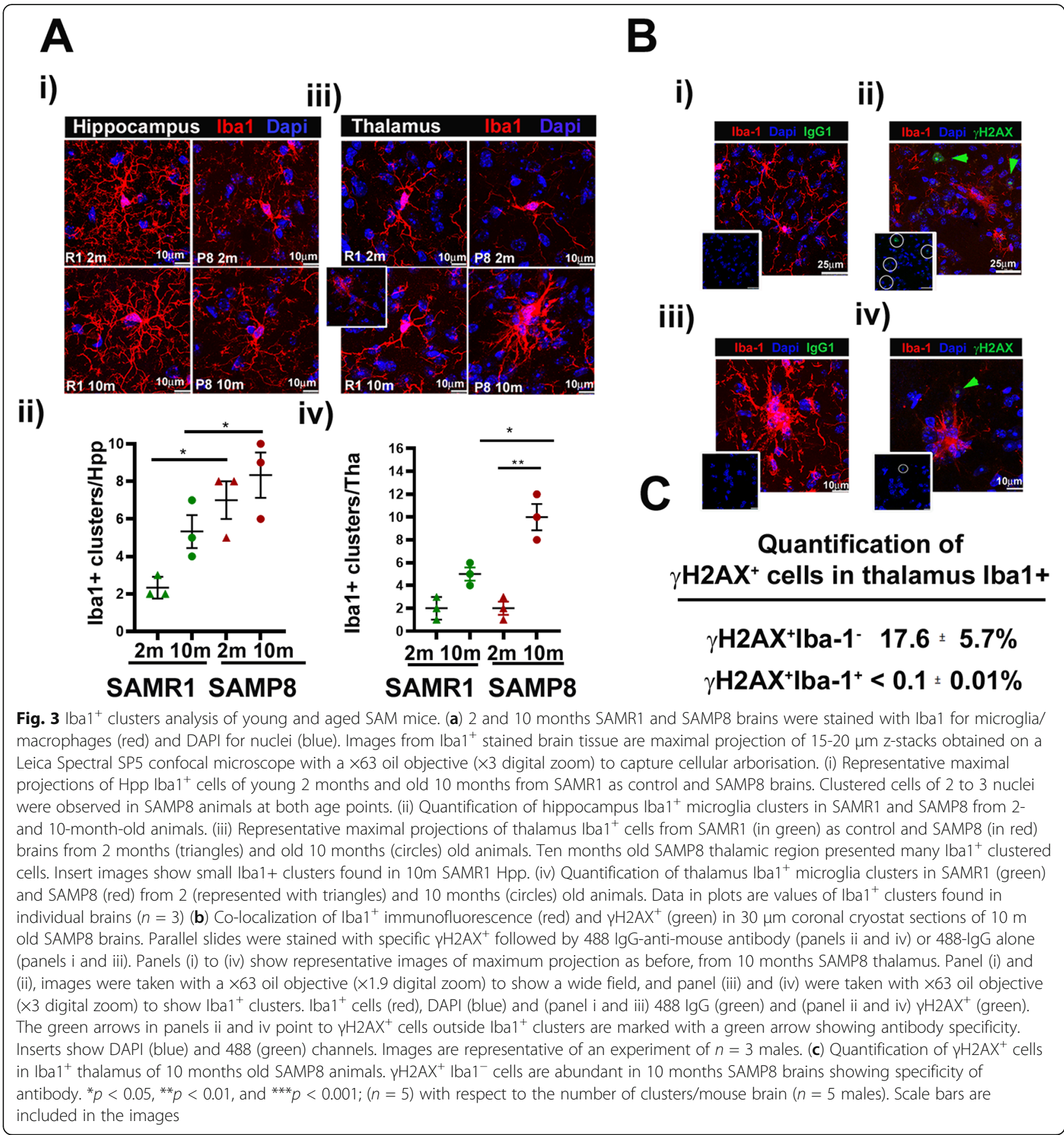

if $\mathrm{Iba}^{+}$clusters observed in 10 months SAMP8 brains were in fact activated microglia described as $\mathrm{Ibal}^{+}$ $\mathrm{MHCII}^{+}$cells. Our analyses showed that these Iba1 ${ }^{+}$ clusters were negative for MHCII. The lack of staining was not due to technical issues, since we observed a good staining of $\mathrm{MHCII}^{+}$cells in choroid plexus. In fact, we could detect a clear increase of $\mathrm{Ibal}^{+} \mathrm{MHCII}^{+}$cells staining in the choroid plexus of aged SAMP8 compared with young 2 months SAMP8 brains. Therefore, our studies indicate that thalamic $\mathrm{Iba}^{+}$clusters are not enriched in $\mathrm{MHCII}^{+}$cells in aged SAMP8 BP (Additional Fig 1S).

The number of hippocampal lba $1^{+}$cells differs between aged senescent and control mouse strains

It has been described that the aging process might affect the number of $\mathrm{Iba1}^{+}$cells in the brain [77] and particularly in the Hpp. These analyses have been performed as well in aged SAMP8 mice, in which an increase in CD11b staining has been described in this 
area [78]. We have analyzed if our animals recapitulate this characteristic feature. To focus on a specific brain area that would allow us to better compare the different strains and age samples, we chose to perform stereology measurements in the Hpp as specified in material and methods. Briefly, we performed analyses of 6 coronal sections separated $300 \mu \mathrm{m}$ one to each other from young ( 2 months) and elderly animals (10 months) as in Fig. 4a, panel ii. These coronal sections correspond approximately to Bregma -1.2 to $-2.7 \mathrm{~mm}$ from [54] reference atlas. Coronal brain slices were stained with anti-Iba1 antibodies and number of $\mathrm{Ibal}^{+}$cells were evaluated. Hpp: DG and CA1 areas, as specified in Fig. 4a panel iii, were analyzed. Surprisingly, but very reproducible, immunohistochemical analyses of total $\mathrm{Iba}^{+}$ cells in 2 months SAMP8 Hpp showed a significant reduction of $\mathrm{Ibal}^{+}$cells compared to 2 months old SAMR1 control brains. This decrease in Iba1 ${ }^{+}$cells was further observed in 10 months old SAMP8 brains, when compared with their 10 months SAMR1 controls (Fig.

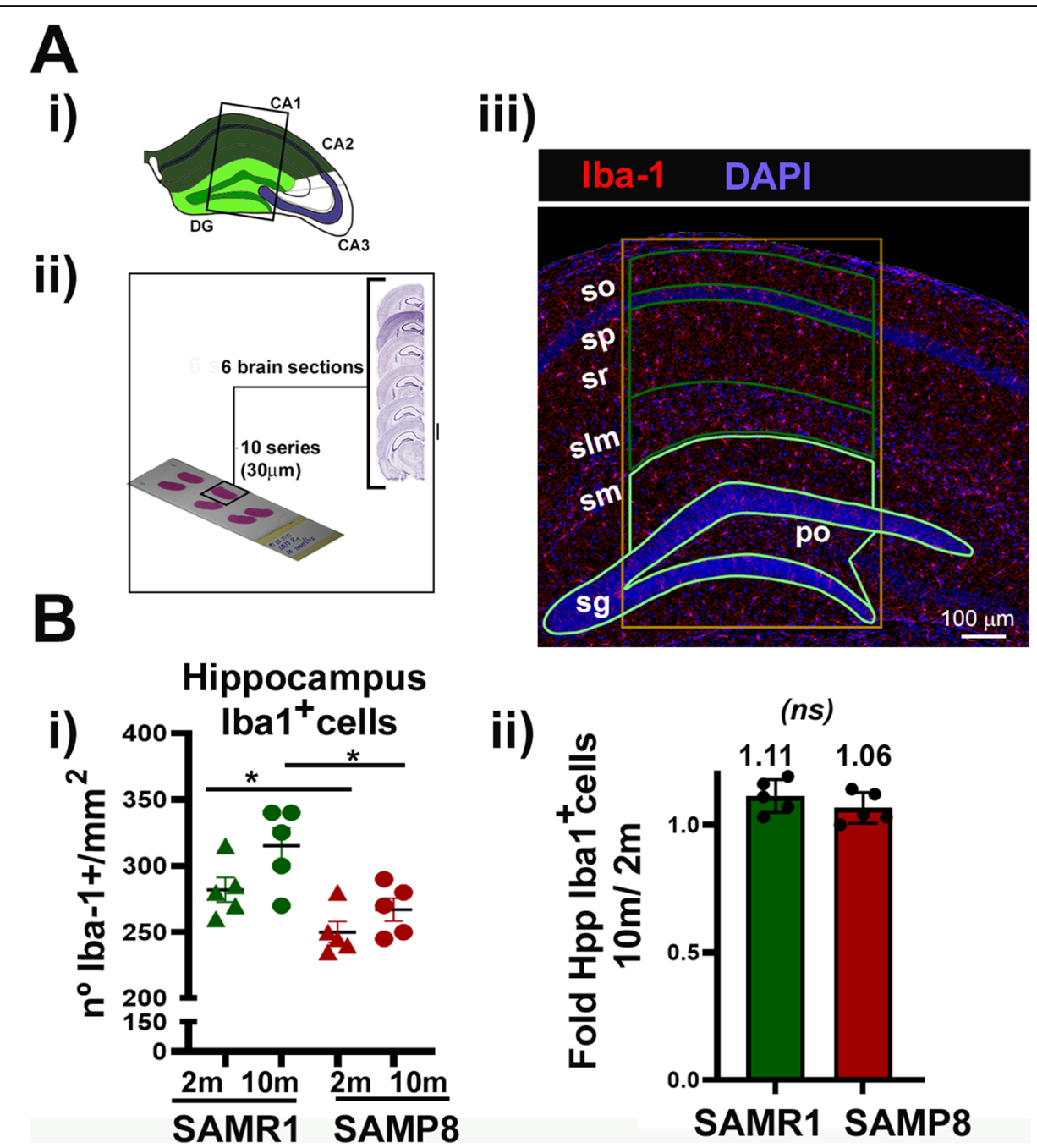

Fig. 4 Evaluation of $\mid \mathrm{ba} \mathrm{1}^{+}$cells in the hippocampus of SAM mice aged 2 and 10 months. Thirty micrometers brain coronal cryostat sections obtained as in material and methods were stained with Ibal (red) and nuclei with DAPI (blue). (a) (i) Hpp area used in the quantification of Iba1 ${ }^{+}$ are surrounded by a box, differing in CA1 (cornus ammonis, dark green) and DG (dentate gyrus, soft green), as shown in the scheme. (ii) Scheme of sample collection: six coronal sections, $30 \mu \mathrm{m}$ each, separated $300 \mu \mathrm{m}$ one to each other were collected and processed. Sampling started at first appearance of the infrapyramidal blade of the dentate gyrus (DG) from approximately Bregma $-1.2 \mathrm{~mm}$ to $-2.7 \mathrm{~mm}$. (iii) Representative map of the hippocampus (Hpp) showing the expression of BP $\mid \mathrm{ba} 1^{+}$myeloid cells $\mid \mathrm{ba} 1^{+}$in $10 \mathrm{~m}$ SAMR1 mice and indicating the regions used for counting. Images at $\times 40$ ( $\times 1.7$ digital zoom) were obtained with a Leica SP5 TCS inverted fluorescence confocal microscope and the areas were processed and evaluated with ImageJ. stratum oriens (so); stratum pyramidale (sp); stratum radiatum (sr); stratum lacunosum-moleculare (sm); stratum moleculare (sm), granule cell layer (sg); polymorph layer (po). Scale bars are included in the image. (b) (i) Quantification of Iba ${ }^{+}$cells in the area described in 2 months (triangles) and 10 months (circles) SAM mice. Data are number on $\mid \mathrm{bba} 1^{+}$cells per individual Hpp ( $n=5$ male). (ii) Fold change of Hpp Iba ${ }^{+}$of 10 months versus 2 months in SAMR1 and SAMP8 mice. ${ }^{*} p<0.05 ;{ }^{* *} p<0.01$, and ${ }^{* * *} p<0.001$ with respect to Iba$1+/ \mathrm{mm}^{2}$ cells in Hpp from SAMR1 $2 \mathrm{~m}(n=5$ males). In (i) and (ii) SAMR1 data are shown in green and SAMP8 in red 
4b, panel i). Therefore, differences between strains complicated further comparisons of aged SAMP8 mice and SAMR1 mice. To eliminate the "strain factor," we evaluated and compared fold increase of $\mathrm{Iba}^{+}$cells of aged (10 months) versus ( 2 months) in each of the strains. As shown in Fig. 4b, panel ii, our results in Hpp $(\mathrm{CA} 1+\mathrm{DG})$, indicate that there are not clear differences in $\mathrm{Iba}^{+}$cells with age, even in 10 months old SAMP8 animals that show clear phenotypical changes associated to age reviewed in [20].

A way to assess the number of $\mathrm{bMyC}$ present in the brain is by isolating brain cells followed by flow cytometry analyses of the different existing cellular populations. bMyC are the major player in inflammation and they are characterized by the expression of the panhematopoietic marker CD45 and the myeloid marker CD11b (see introduction). We isolated 2 months and 10 months old SAMP8 and control SAMR1 brain parenchymal cells without the meningeal and plexus membranes (BP) cells by using $30 \%$ Percoll gradient. The amount of alive cells obtained after this procedure was not statistically different between animals groups. For aged animals, we obtained $1.2 \pm 0.1$ million cells/brain from 10 months SAMR1 animals and $1.1 \pm 0.1$ million cells/brain from 10 months old SAMP8. Once those cells were we follow the gating strategy presented in Additional Fig 2s to eliminate doublets and further analyzed DAPI positive, alive cells. In Fig. 5a, panels i and ii, we present the number of $\mathrm{CD}_{4} 5^{+}$cells isolated per brain in 10 months aged SAMR1 (green bars) and SAMP8 (red bars). The number of isolated $\mathrm{CD} 45^{+}$bMyC did not significantly change between all the groups analyzed, and particularly in 10 months aged SAMR1 $(49 \pm 8 \%)$ and SAMP8 (43 \pm 10\%) $n=10$ (Fig. 5a, panel iii). There is a clear discrepancy about the difference observed between $\mathrm{Iba1}^{+}$ immunohistochemical analysis (Fig. 4) and $\mathrm{CD} 45^{+}$cells cytometry analyses (Fig. 5a). To clarify this point, we evaluated the expression of Iba1 mRNA transcripts in both strains at the different age analyzed and observed that in fact, there is a clear decrease in the expression of Aif-1 gene encoding Iba1 in 2 months SAMP8 animals, in accordance with the results obtained in our immunofluorescence analyses (Fig. 4). To assess if there were less Iba $1^{+}$cells, we evaluated the expression of a different molecule, that has been previously shown to be expressed mainly in microglia cells in the brain, the fractalkine receptor (CX3CR1) [79]. In this case, the amount of specific $C \times 3 \mathrm{cr} 1$ transcript present in all the groups analyzed differed only slightly (Additional Fig 3s). This indicates that the number of BP microglia cells do not change greatly although there is a clear decrease in the expression of Iba 1 gen (Aif-1), which should be further studied. Since we have not found significant agedassociated changes in the number of $\mathrm{Iba}^{+}$between aged
10 months SAMR1 and SAMP8 by immunofluorescence analyses (Fig. 4b, ii), together with the fact that $\mathrm{CD} 45^{+}$ isolated cells from 10 months SAMP8 BP do not show significant differences compared to 10 months SAMR1 control (Fig. 5a, iii), we concluded that the number of $\mathrm{BP}$ bMyC in the SAMP8 brain do not change with age. Furthermore, we suggest that the isolation and evaluation of isolated CD45 $\mathrm{BP}$ cells is the method of choice to analyze changes between different mice strains and conditions.

\section{The number of $B P C D 45^{\text {high }}$ cells do not increase in age senescent SAMP8 mice}

Immunosurveillance takes place in the central nervous system (CNS) in spite of its specific anatomic features conferring a certain degree of isolation from the periphery [80]. The blood-brain barrier (BBB) prevents free trafficking across the brain vasculature but immune cells can cross the endothelium of post-capillary venules or reach the brain through the choroid plexus and the leptomeninges $(\mathrm{mCh})$ mainly under inflammatory conditions. To analyze if there was an increase in the number of $\mathrm{CD} 45^{+}$from the periphery, we stained isolated cells from the different strains and ages with anti-CD45 and CD11b antibodies (Fig. 5b), and observed more clearly that $\mathrm{BP} \mathrm{CD}_{4} 5^{+}$cells can be differentiated in two clear populations: one that express medium levels of CD45 $\left(\mathrm{CD} 45^{\mathrm{m}}\right.$, red box), and cells with a high expression of $\mathrm{CD} 45\left(\mathrm{CD} 45^{\mathrm{h}}\right.$, blue box). We found that there were not significant differences between isolated cells comparing age and strains. As mentioned before, the existence of brain $C D 45^{\mathrm{h}}$ positive cells has been correlated with the existence of peripheral $\mathrm{CD} 45^{+}$cells in the brain. Cerebral invasion of lymphocytes crucially depends on the interaction of the leukocyte very late antigen-4 (VLA-4) with vascular cell adhesion molecule-1 (VCAM-1) on endothelial cells $[81,82]$. VLA-4 (integrin $\alpha 4 \beta 1$ ) is an integrin heterodimer consisting of an alpha chain (integrin $\alpha 4=$ CD49d) and a beta chain (CD29). Therefore, the expression of CD49d has been used to trace brain myeloid cells originated in the periphery [83]. CD $45^{\mathrm{h}}$ cells in our cellular BP preparation were CD3 negative (data not shown) but mainly positive for CD49d (Fig. 5b, panel ii b, blue box), and this marker did not stain CD45 ${ }^{\mathrm{m}}$ cells (red box). To ensure that $\mathrm{CD} 45^{\mathrm{m}}$ cells correspond to bonafide microglia, we stained $\mathrm{CD} 45^{+}$cells with specific microglia markers such as P2RY12 receptor. As shown in Fig. 5b, panel ii c), this marker stained the majority of CD $45^{\mathrm{m}}$ brain cells, corresponding to $92 \pm 4 \%(n=4)$ of P2RY12 ${ }^{+}$cells from total $\mathrm{CD} 45^{+}$BP cell isolated with not significant differences between age and strains analyzed. The quantification of $C D 45^{\mathrm{h}}$ cells in aged animals, in which BBB breach might occur, did not show significant differences between 10 months SAMP8 BP $(4.2 \pm$ 


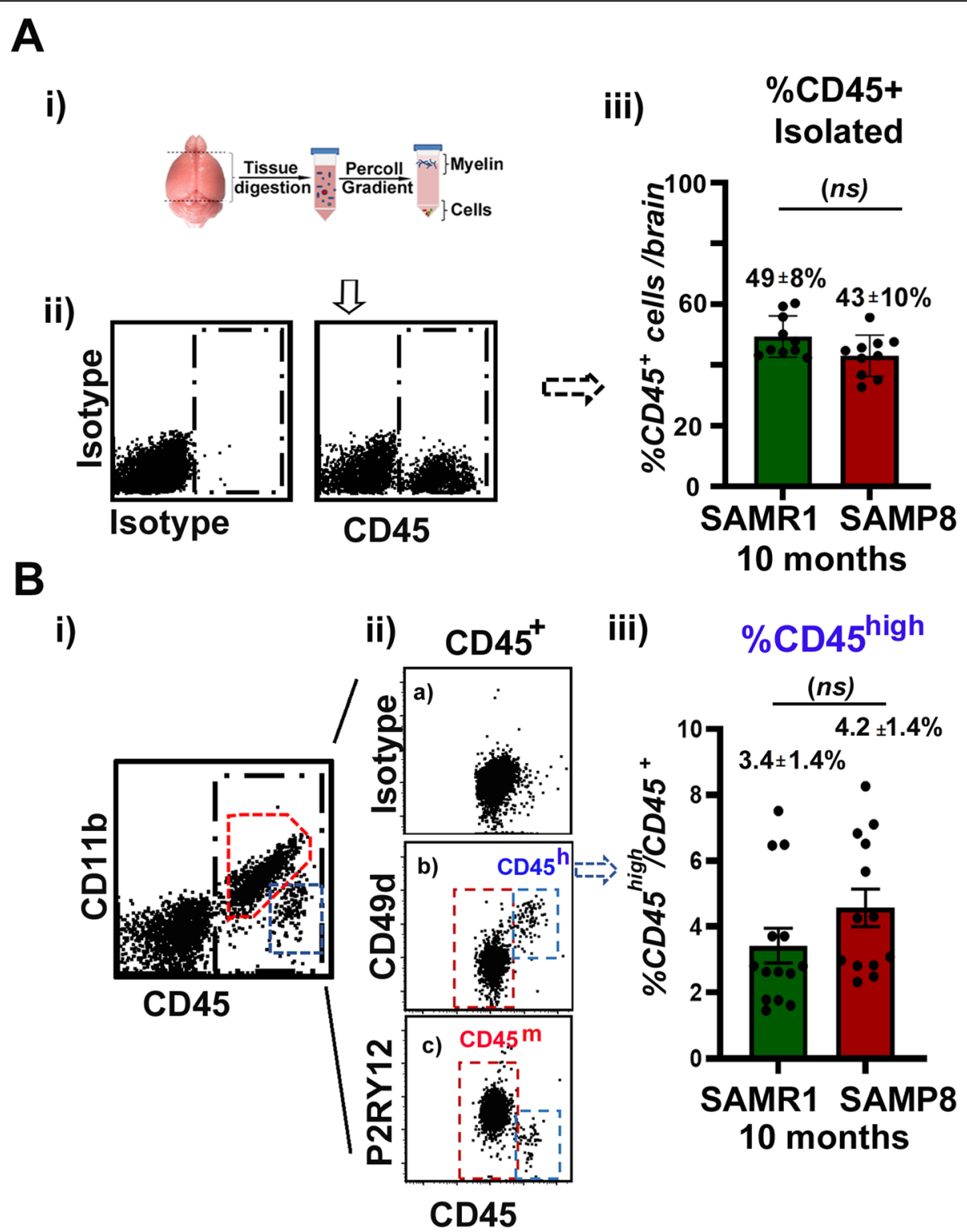

Fig. 5 Isolation and quantification of CD45-positive brain cells. (a) (i) Cartoon representing brain cells isolation procedure. (ii) Representative flow cytometry dot plots of live cells isolated from brain (except cerebellum and olfactory bulb (OB) and $\mathrm{m} / \mathrm{Ch}$ ). Cells were isolated and stained with control isotype antibody (APC-labeled rat lgG2b) or with APC-labeled rat anti-mouse CD45. Black box marks CD45 cells. Gating strategy was as presented in additional Fig 2s. (iii) The box and whisker plot shows arithmetic mean \pm 25 -75 quartile (box) and minimum and maximal values (lines) $(n=10)$ of the percentage of total CD45 cells isolated from 10 months SAMR1 (green) and SAMP8 (red) brains. (b) (i) Cells were stained with PE-Cy7-labeled rat anti-mouse CD45 together with 488 rat anti-mouse CD11b. CD45 ${ }^{\mathrm{m}}$ cells are marked with red box and CD45 cells with a blue box. (ii) Cells were stained with PE-Cy7 rat anti-mouse CD45 plus APC rat lgG2b as isotype control (a); APC rat anti-mouse CD49d (b) or APC rat anti-mouse P2RY12 (c). Shown are representative dot plots obtained for cells isolated from 10 months SAMP8 animals that were similar to cell preparations from young and old SAMR1 and SAMP8 animals. (iii) Box and whisker plot as in panel A iii $(n=10)$, representing the percentage of total CD45 ${ }^{\mathrm{h}}$ cells isolated from 10 months SAMR1 (green) and SAMP8 (red) brains. (ns) Indicates no statistically difference between specified groups applying statistical methods as in material and methods

$1.4 \%, n=4)$ compared to their 10 months SAMR1 control $(3.4 \pm 1.4 \%, n=4)$. In our hands, the number of $\mathrm{CD} 45^{\mathrm{h}}$ in aged animals was comparable to that observed in young 2 months control strains [55]. These results are further discussed in the following section.
Inflammatory profile in isolated brain myeloid cells As mentioned above, a characteristic of neuroinflammation is phenotypic glial activation and de novo production of immune signaling molecules. Both astrocytes and microglia undergo cellular hypertrophy with age, and it has been 
shown that pro-inflammatory cytokines levels increase in elderly subjects $[18,22,84]$. IL-1 $\beta$ is intimately involved in the elaboration of acute neuroinflammatory processes in vivo, and exposure of the rodent brain to IL-1 $\beta$ elicits rapid, robust activation of both astrocytes and microglia. In the senescent model SAMP8, an increase of inflammatory markers has been described in blood plasma and total brain tissue [42]. Therefore, we asked if a source of IL-1 $\beta$ in this model was in fact the bMyC cellular compartment, since they constitute the main cell type involved in the brain inflammatory process. We analyzed $\mathrm{Il}-1 \beta$ expression in $\mathrm{CD} 45^{+}$bMyC preparations from BP. Strategy is summarized in Fig. 6a, panel i for BP, and from border-associated myeloid cells contained in $\mathrm{m} / \mathrm{Ch}$ preparations as in Fig. $6 \mathrm{~b}$, panel i. $I l-1 \beta$ transcripts from 2 and 10 months old SAMP8 and SAMR1 cellular preparations were analyzed by qRTPCR as in material and methods. We express our data in delta $\mathrm{Ct}(\mathrm{dCt})$ as the $\mathrm{Ct}$ of the specific transcript minus $\mathrm{Ct}$ of $36 \mathrm{~b} 4$ as housekeeping control (Fig. 6a and b, panel ii), that more clearly shown the difference between very different tissues. As shown in Fig. 6, Il-1 $\beta$ mRNA expression was significantly higher in BP preparations from aged 10 months old SAMP8 when compared with 10 months old SAMR1. dCt data from $\mathrm{m} / \mathrm{Ch}$ preparation were higher, indicating a lower abundancy of specified transcript. In fact, $\mathrm{Il}-1 \beta$ transcripts were hardly detected in $\mathrm{m} / \mathrm{Ch}$ when compared with BP cellular preparations. Figure $6 a$ and b, panel iii shows the same data displayed as quantification relative to healthy 2 months SAMR1 animals that was given an average value of 1 . Brain border $(\mathrm{mCh})$ bMyC were analyzed to study the possible contribution of peripheral inflammation to brain $I l-1 \beta$ expression detected in aged SAMP8 BP (Fig. 6a).

A raise in IL-1 $\beta$ parenchymal expression in the rodent brain might increase the expression of other proinflammatory cytokines, leukocyte chemotactic chemokines, cell surface adhesion molecules, cyclooxygenases, and matrix metalloproteases within the brain parenchyma. We analyzed in our experimental groups the expression of pro-inflammatory cytokines such as tumor necrosis factor-alpha (TNF- $\alpha$ ) and interleukin 6 (IL-6). Furthermore, IL-1 $\beta$ elevations have been implicated in trafficking of peripheral immune cells to the brain mediated by cytokines such as CCL2 (reviewed in [8]); therefore, we included the expression of this cytokine in our analyses. As shown in Additional Fig 4s, Tnf- $\alpha, I l-6$, and $C c l 2$ mRNA expression was significantly diminished in young ( 2 months) SAMP8 BP cellular preparations compared to 2 months old SAMR1, similarly to the data obtained for $\mathrm{Il}-1 \beta$. Although mRNA values of these cytokines were variable in 10 months old animals, an increase of $\mathrm{Il}-1 \beta$ was observed in BP from SAMP8-aged animals (represented as a lower dCt: $\mathrm{Ct}_{\text {gene }}-\mathrm{Ct}_{3664}$ ). When $\mathrm{m} / \mathrm{Ch}$ preparations were analyzed, there were not significant changes in the expression of these markers between all the groups tested. We noticed that the expression of cytokines in $\mathrm{m} / \mathrm{Ch}$ was very low for all the pro-inflammatory markers and lower than in BP preparations. Thus, these results indicate that aged SAMP8 bMyC express higher mRNAs levels of proinflammatory markers mainly in the brain parenchyma and not in border $\mathrm{bMyC}$ from $\mathrm{m} / \mathrm{Ch}$ membranes. Consistent with these data, we have not detected a significant increase in systemic inflammation in 10 months SAMP8 animals, since our preliminary analyses do not detect an increase in inflammatory markers in blood plasma of these animals (data not shown).

Response to inflammatory stimuli in the senescent model The use of lipopolysaccharide (LPS) as a robust systemic inflammogen has been widely described (see introduction). For these experiments, we selected a low dose of LPS (i.p. injection 0.5 to $1 \mathrm{mg} / \mathrm{kg}$ ) that does not cause mouse lethality and only induces a limited inflammatory response $[85,86]$. While high doses of LPS produce immune activation and lethality characteristic of septic shock, low doses such as the one selected in our studies reproduce the chronic inflammation status found in many neurological diseases. Furthermore, this compound has been used to test a phenomenon called "priming" of aged innate immune response (see introduction). We analyzed if old SAMP8 brains recapitulate this phenotype characteristic of brain aging.

First, we evoked systemic inflammation by LPS and analyzed the expression of $I l-1 \beta, T n f-\alpha, I l-6$, and $C c l 2$ mRNAs at different times, to define the time window for the expression of pro-inflammatory markers in our brain cellular preparation. In accordance with literature, after $3 \mathrm{~h}$ of LPS $(1 \mathrm{mg} / \mathrm{kg})$ intraperitoneal injection, brain tissue and isolated bMyC expressed high levels of all these pro-inflammatory markers [19, 87]. We evaluated the expression of these molecules in cellular preparations from BP and from border-associated $\mathrm{m} / \mathrm{Ch}$ cells. As shown in Fig. 7a, expression of these molecules was greatly enhanced by LPS in BP, although maximal LPS-dependent transcription of these cytokines was observed in $\mathrm{m} / \mathrm{Ch}$ border-associated cells, as shown in Fig. 7b. Expression kinetics were faster in $\mathrm{m} / \mathrm{Ch}$ than in BP cells as correspond to a systemic model of infection (data not shown).

Once established the time and dose of the inflammogen, and the fact that systemic LPS was sensed by the BP cells inducing the expression of proinflammatory markers, we analyzed the inflammatory state in bMyC cell preparation as before. Senescent 10 months old SAMP8 and control SAMR1 were injected with saline solution (ss) and LPS (as in material and methods), and after $3 \mathrm{~h}, \mathrm{BP}$ and $\mathrm{m} / \mathrm{Ch}$ cells were 


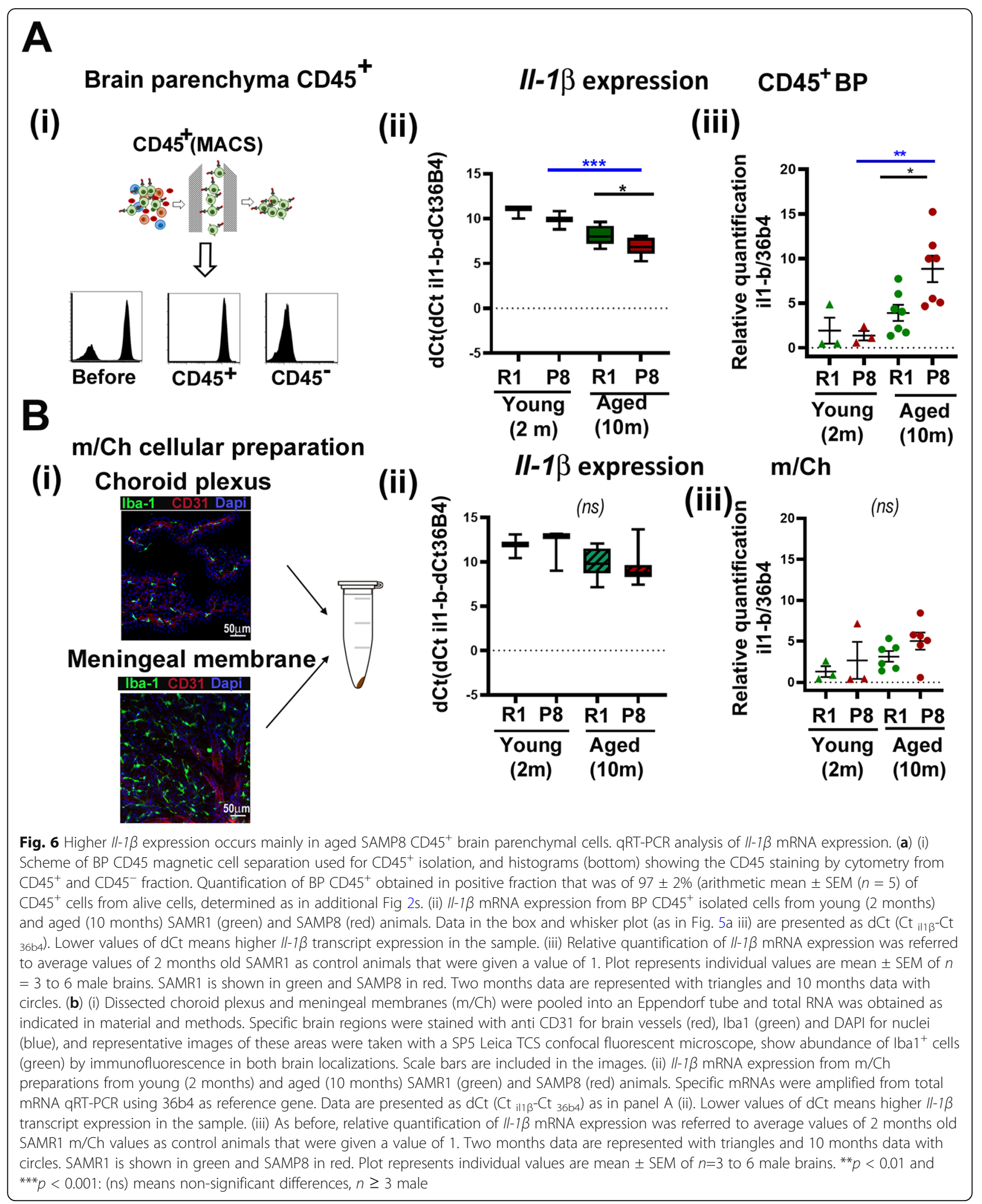




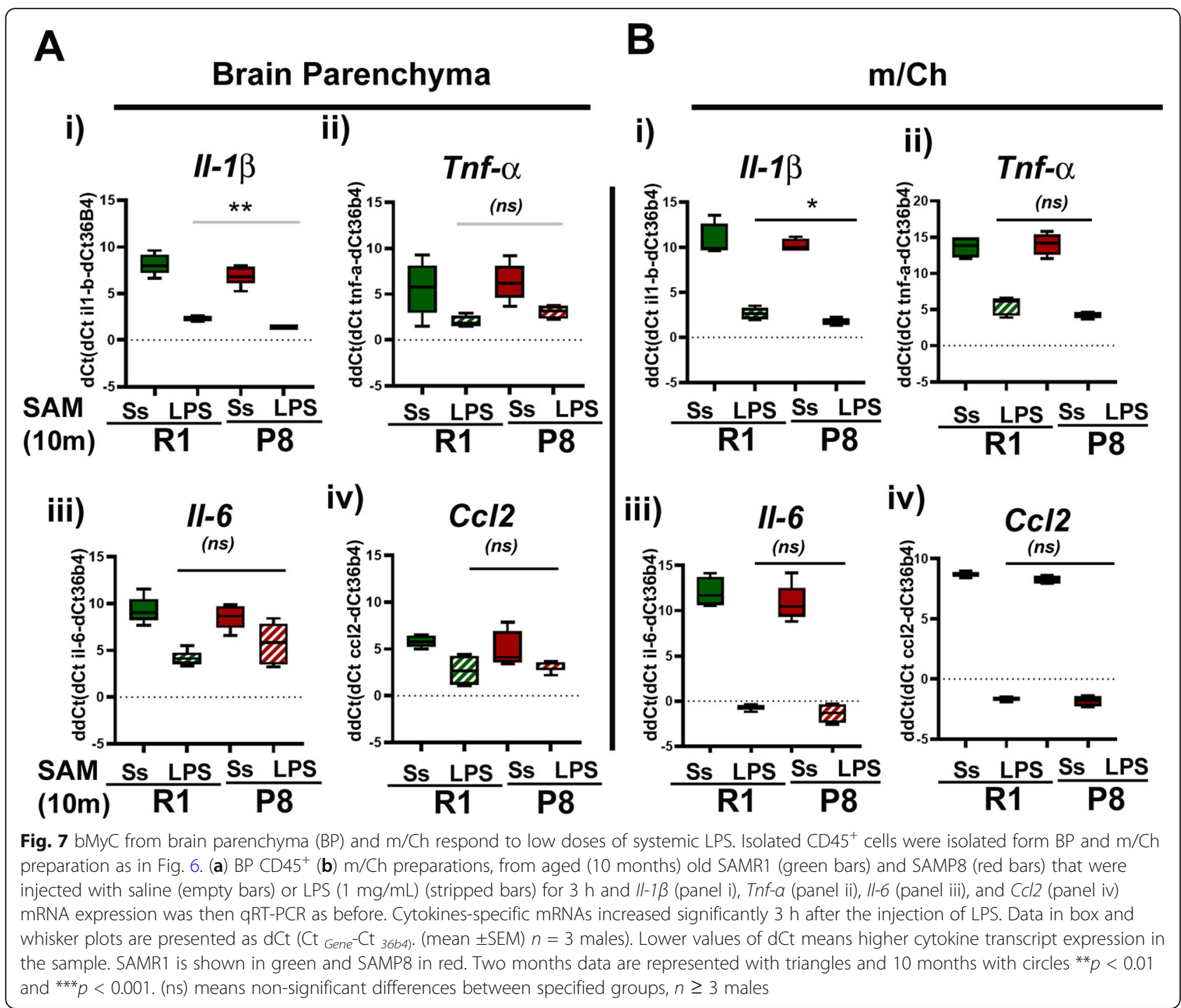

isolated. Levels of inflammatory markers were analyzed as previously described. As shown in Fig. 7, LPS induced all the pro-inflammatory markers expression studied in both animal strains, represented as $\mathrm{dCt}: \mathrm{Ct}_{\text {gene }}-\mathrm{Ct}_{36 b 4} \mathrm{It}$ was noticeable that only the $\mathrm{Il}-1 \beta$ expression was significantly higher in aged LPS-challenged SAMP8 animal compared to their control LPS-SAMR1. This phenomenon agrees with previous results in which there are an age-dependent priming of microglia from aged brains $[19,51]$, which we show is recapitulated in aged SAMP8 animals.

\section{Discussion}

SAMP8 as a model of neurodegeneration-associated neuroinflammation

Brain aging in mice and humans leads to morphological and functional changes that are considered hallmarks of abnormal activity. One of these morphological changes is the appearance of pathological granular structures in the Hpp and their progressive expansion with age [88]. These anomalous PAS positive aggregates have been described in aged SAMP8 mouse, and their nature has been discussed and reviewed in [61, 63]. Although SAMP8 animals have been proposed as a model for ageassociated neurodegenerative diseases such as late onset Alzheimer disease (LOAD) (reviewed in [20]); the brain myeloid cells repertoire in the SAMP8 model has not been fully described. Early findings by Takeda's group described the presence of accumulation of CD $45^{+}$ $\mathrm{CD}_{11 \mathrm{~b}^{+}}$cells by immunohistochemical analyses in the CA1 region of SAMP8 mice hippocampus [78], concluding that there was an increase in microglia proliferation and the appearance of reactive/activated microglia as cells with thick and short processes and strong staining of CD11b. The effect of aging alone in the number of microglia cells is controversial in the literature. Some 
authors do not observe an increase of microglia cells in male mice aged Hpp [89]; other authors found that the number of microglia cells is decreased in the aged hippocampal area [90, 91], or increased when female animals were analyzed [89]. These discrepancies might be due to different mouse strains, animal age or the fact that different markers for microglia detection and methods are used. A careful comparison of all these results awaits further analyses. In most of the studies, Iba1 staining has been used as a marker for microglia identity/activation, and Iba1 increased expression has been further reported in aged CA1 rat by immunoblot analyses [92]. Here, we have re-analyzed changes in the number and morphology of $\mathrm{Iba}^{+}$cells associated to senescent-related processes in the SAMP8 brain. Our results did not support an age-dependent increase of microglia cells in the aged SAMP8 brain by two ways. First, we performed stereology mapping to analyze the number of BP Iba1 ${ }^{+}$cells by immunofluorescence. These studies allowed us to compare more robustly different brain areas from a variety of mouse strains and age by measuring the expression of $\mathrm{Iba}^{+}$cells $/ \mathrm{mm}^{2}$ in each strain. Second, the evaluation of the number of isolated CD $45^{+}$brain cells in aged SAMP8 compared to SAMR1 control (as shown in Fig. 5), allowed us to conclude that, at the age evaluated $(10 \mathrm{~m})$, there was not a significant increase of hippocampal $\mathrm{Iba}^{+}$cells in the old senescent animal SAMP8, with clear hallmarks compatible with brain degeneration. We clearly observed that young 2 months old SAMP8 presented less amount of Hpp Iba1 ${ }^{+}$ staining when compared to their SAMR1 controls, which make difficult the comparison between strains. No fold increase differences between 2 and 10 months samples was observed (as in Fig. 4), and therefore we reached to the conclusion that the number of Iba $1^{+}$cells in the aged senescent mice with respect to their control do not increase. The meaning and final outcome of this reduction of Iba1 ${ }^{+}$staining in the young SAMP8 mice remains to be fully investigated.

One possibility to reconcile our observation to those previously reported, in which they observed an increase in the microglia number with age, could be the use of older animals (12 months old) that might account for the difference in number of $\mathrm{Iba}^{+}$cells observed, although not significantly differences at 10 months were observed (Fig. 4). Microglia cells increase, as CD11b ${ }^{+}$ cells, has also been described in response to SAMP8 aging, a process that is concomitant with age-dependent changes in BBB [93]. Nevertheless, we have not been able to detect such an increase, nor proliferation in the BP (Iba1 ${ }^{+} \mathrm{Ki}^{+} 7^{+}$cells) by immunofluorescence (data not shown). Furthermore, we could not detect significant changes in the number of $\mathrm{CD} 45^{+}$isolated from these mice (Fig. 5a), nor a substantial increase in the amount of BP CD45 $5^{\mathrm{h}}$ cells from the periphery when compared 10 months old SAMP8 with their SAMR1 controls (Fig. $5 b)$. These analyses are an experimental challenge since they required a careful manual dissection of meningeal membranes (piamater) and choroid plexus, which contained $\mathrm{CD} 45^{\mathrm{h}}$ cells. The novel description of cellular markers that differentiate proper $\mathrm{CD} 45^{+}$brain cells from those of peripheral origin will clearly help to confirm the permeability capacity of immune cells with aging.

The activation state of aged SAMP8 microglia can be studied by the expression of MHCII. MHCII expression is required to establish a robust adaptive immunity in the brain and periphery. The entry and activation of $\mathrm{T}$ cells in the brain parenchyma requires a pre-existing interaction of these cells with antigen presenting cells. In non-injured young brains, the expression of MHCII is low and mainly restricted to perivascular spaces and border associated macrophages in $\mathrm{m} / \mathrm{Ch}[55,94]$. During the aging process, a strong increase in brain $\mathrm{MHCII}^{+}$ cells has been described in different animal models [92, 95-97]. We evaluated the presence of $\mathrm{Iba}^{+} \mathrm{MHCII}^{+}$ cells by immunofluorescence analyses in 10 months aged SAMP8 brains (Additional Fig 1s). $\mathrm{MHCII}^{+}$cells in the BP of young 2 months SAMP8 were hardly detectable, and 10 months old SAMP8 animals did not express higher amount of $\mathrm{Ibal}^{+} \mathrm{MHCII}^{+}$cells in BP, mainly in thalamic areas, compared to their young 2 months SAMP8 control. This expression was very low, hardly detectable and restricted to perivascular areas, as seen in control animals [55]. To ensure that there were no technical problems with the immunofluorescence analyses, we studied the expression of MHCII antigen in the brain $\mathrm{m} / \mathrm{Ch}$ border. We found a clear increase of $\mathrm{Iba}^{+}$ $\mathrm{MHCII}^{+}$cells in $\mathrm{m} / \mathrm{Ch}$ of $10 \mathrm{~m}$ SAMP8 compared to their 2 months controls. These experiments could not been performed in SAMR1 mice, since the antibody used for these analyses did not recognize the specific haplotype of the SAMR1 animals (H-2Ks) [98]. When 10 months aged control mouse strain such as CD1 was analyzed instead, we could not observe an increase in the number of $\mathrm{Iba}^{+} \mathrm{MHCII}^{+}$cells in 10 months old animals, although the number of MHCII present in the $\mathrm{m} / \mathrm{Ch}$ in young animals was higher (Additional Fig 1s). Age-dependent changes in the immune system and BBB function has been described and reviewed [99]. Our data show that $\mathrm{MHCII}^{+} \mathrm{Iba1}^{+}$cells are a minority in $\mathrm{BP}$ and the expression of this activation marker is mainly found in the $\mathrm{Iba}^{+}$cells of border $\mathrm{m} / \mathrm{Ch}$ areas from aged SAMP8 mouse. Furthermore, this implies that the expression of this activation marker is not present in the clustered Iba $1^{+}$cells observed in aged SAMP8 mouse.

For the isolation of cells from two of the main bMyC enriched areas, BP and $\mathrm{m} / \mathrm{Ch}$ [55], removal of myelin and cell debris after tissue digestion is a critical step for 
flow cytometry analysis. Percoll density gradients have been widely used for brain immune cells isolation [100, 101]. Different density gradients such as 30\% [102-104] and $30-70 \%[19,100,105]$ have been used. In our hands, $30 \%$ Percoll density gradients produce more than threefold increase in the total cell recovery with a better viability. To achieve greater purity, we used magnetic-beads based affinity purification (MACS) with a yield of $97 \pm$ $2 \%(n=10) \mathrm{CD}^{2} 5^{+}$positive cells (cartoon in Fig. 6a). BP preparation will formally contain proper microglia cells, perivascular macrophages and blood-derived macrophages that might infiltrate the CNS and contribute to the pathological sequelae. The Hpp is an irrigated brain tissue, and since changes in BBB permeability have been reported in the SAMP8 [106, 107]; it is possible that peripheral myeloid cells enter the aged SAMP8 brain. As shown in Fig. 5, our BP preparations, in the most inflammatory conditions (10 months aged SAMP8 animals), contained mainly proper microglia cells with a medium CD45 expression as described before. Our results indicating that in aged SAMP8 mouse BBB permeability for peripheral lymphocytes was neither enhanced compared to aged control SAMR1 animals nor to young animals (Fig. 5), are in line with previous studies [108], although in contrast to the results described by other authors [106]. This topic has been recently reviewed in [99].

Increased levels of pro-inflammatory cytokines such as IL- $1 \beta$, TNF- $\alpha$, and IL- 6 in the aged CNS has been described before $[18,19,84,109,110]$. Here, we have studied mRNA expression of these cytokines in bMyC-enriched preparation of SAMP8 and SAMR1 from $\mathrm{BP}$ and $\mathrm{m} / \mathrm{Ch}$ with age. Our data in the aged senescent model are consistent with the increment of inflammatory markers seen in aged brain tissue and aged isolated brain.

Since IL- $1 \beta$ is intimately involved in elaboration of acute and chronic neuroinflammatory processes in vivo (revised in [43]); here, we show that $I l-1 \beta$ expression is greatly enhanced in aged SAMP8 bMyC from BP but not in $\mathrm{m} / \mathrm{Ch}$ (Fig. 6). These results are in accordance to preliminary data indicating that systemic proinflammatory markers in aged 10 months SAMP8 animals do not differ greatly from 2 months or their 10 months SAMR1 control (data not shown). Parenchymal expression of $I l-1 \beta$ in rodents increases expression of other pro-inflammatory cytokines and leukocyte chemotactic chemokines within the brain parenchyma [43, 111]. Importantly, IL-1 $\beta$ is capable of triggering further increases in its own expression as evidenced by murine Il-1 $\beta$ induction following human IL-1 $\beta$ administration or expression in the brain $[43,112]$. Therefore, an increment on the amount of IL- $1 \beta$ expression will lead to a neuroinflammatory cascade that it is restricted to the brain tissue in the absence of systemic challenges.
We have evaluated further $\mathrm{bMyC}$ response to low LPS dose simulating mild inflammatory conditions and not septic shock. The LPS dose used in our experiments $(0.5$ to $1 \mathrm{mg} / \mathrm{kg}$ ) is far from the $\mathrm{LD}_{50}$ for LPS in mice (5 to $15 \mathrm{mg} / \mathrm{kg}$ ) and did not cause significant lethality [85, 86]. Despite this low dose, BP bMyC were able to sense this inflammogen and produced LPS-dependent cytokine increase, indicating that the BBB-protected microglia cells are able to sense systemic inflammatory conditions. These results are in accordance to recent data indicating that the entire brain exhibited the ability to respond to endotoxemia provoked by LPS producing a wide repertoire of cytokines [113]. How and which are the receptors involved in LPS-inducible inflammation in the brain remains to be fully understood, although a role for TLR2 receptor has been suggested [50].

Aging dependent BBB permeability allows the entrance of peripheral immune cells in the SAMP8 model in response to peripheral inflammation. This phenomenon could play a role in the amplification of neuroinflammation processes in response to systemic inflammation and how to manipulate this entrance will be the focus of future research effort.

\section{Conclusions}

Neuroinflammation (NIF) plays an important role in aged associated degeneration of central nervous system (CNS). Here, we analyzed the brain myeloid cells repertoire in the senescent accelerated prone aged (SAMP8) mouse model and propose this model to study age-associated neuroinflammatory events. Although aged hippocampal areas from SAMP8 animals do not show differences in the number of $\mathrm{Iba}^{+}$cells or with age, there are clear phenotypical changes associated to aging and an increment of bMyC inflammatory markers, together with a role in the amplification of the neuroinflammation processes in response to systemic inflammation. The need of experimental models to analyze the role of neuroinflammatory processes in the neurodegeneration associated to aging, opens the possibility to study the response of SAMP8 to novel therapeutic approaches.

\section{Supplementary Information}

The online version contains supplementary material available at https://doi. org/10.1186/s12974-021-02104-3.

\footnotetext{
Additional file 1: Supplementary Fig 1S. Evaluation of $\mathrm{Iba} 1^{+} \mathrm{MHCll}^{+}$ cells in the choroid plexus of 2 and 10 months old SAMP8 and CD1 mice. Representative Iba1 (red), MHCII (green) and DAPI (blue) staining images of coronal sections of choroid plexus (A) from 2 months (triangles) and 10 months (circles) old SAMP8 in red (B) and 2 months and 10 months CD1 in black. Images were obtained with a Leica TCS SP5 inverted fluorescence confocal microscope, using a 40x and 63x objective ( $3 x$ digital zoom) for the magnifications. The images are representative of at least three independent experiments using males. Scale bars are
} 
included in the images. Panels ii) show analysis of the number of $\mid \mathrm{ba} 1^{+}$ $\mathrm{MHCII}^{+}$cells over the total of $\mid \mathrm{ba} 1^{+}$cells. The data show the mean \pm SEM ( $n=3$ to 4 male). ${ }^{*} p<0.05$; (ns) no significant differences between groups.

Additional file 2: Supplementary Fig 2S. Gating strategy for flow cytometry analysis. Cells were obtained and labeled as described in Materials and Methods. (A) Brain parenchyma cells without $\mathrm{m} / \mathrm{Ch}$ (B) $\mathrm{m} /$ Ch isolated cells. Before flow cytometry analysis DAPI $(5 \mu \mathrm{g} / \mathrm{mL})$ was added to determine cell viability. Cells were first gated (P1) based on size and complexity (SSC vS FSC). Doublet discrimination was performed by FSC-H vs FSC-W and SSC-H vs SSC-W analyses, and then PI or DAPI negative cells (i.e. live cells) were selected for further analysis.

Additional file 3: Supplementary Fig 3S. Aif- 1 and $C \times 3 \mathrm{Cr} 1$ in $C D 45^{+}$ brain parenchymal cells. Isolation and quantification of $\mathrm{BP} C D 45^{+}$brain cells as in Fig 6. qRT-PCR analysis of (A) Aif-1 gene and (B) $C \times 3 \mathrm{Cr}$. After extraction of total RNA, CDNA were amplified using SYBR Green Real time PCR methodology using 3664 as reference gene. (i) Show graphs presented as $\mathrm{dCt}\left(\mathrm{Ct}_{\text {gene }}-\mathrm{Ct}_{3664}\right)$. Lower values of $\mathrm{dCt}$ means higher cytokine transcript expression in the sample. (ii) Relative quantification of mRNA expression was referred to average values of $2 \mathrm{~m}$ old SAMR1 as control animals that was given a value of 1 . The data show the mean \pm SEM ( $n=3$ to 4 males). ${ }^{* *} p<0.01$ between specified groups, $\mathrm{n} \geq 3$ males.

\section{Additional file 4: Supplementary Fig 4S. Tnf- $a, I 1-6$ and $\mathrm{CCl} 2$} expression occurs mainly in aged SAMP8 $\mathrm{CD}^{2} 5^{+}$brain parenchymal cells. qRT-PCR analysis of (i) Tnf-a, (ii) II-6 and (iii) CCl2 mRNA expression was then quantified by real-time PCR as before. (A) $\mathrm{CD}_{4} 5^{+}$brain parenchymal (BP) cells as Fig 6. (B) Dissected choroid plexus and meningeal membranes $(\mathrm{m} / \mathrm{Ch})$ were obtained as in Fig $6 \mathrm{~b}$. After extraction of total RNA CDNA were amplified as described in Fig 3s. Data are presented as dCt $\left(\mathrm{Ct}\right.$ gene- $\left.\mathrm{Ct}{ }_{36 \mathrm{~B}}\right)$. Lower values of $\mathrm{dCt}$ means higher transcript expression of specific mRNA in the sample. The data show the mean \pm SEM ( $n=3$ to 4 males). ${ }^{* *} p<0.01$ and ${ }^{* * *} p<0.001$ between specified groups.

\section{Abbreviations}

CNS: Central nervous system; SAMP8: Senescent accelerated prone: SAMR1: Senescence resistant; NIF: Neuroinflammation; AD: Alzheimer disease; LOAD: Late onset Alzheimer disease; bMyC: Brain myeloid cells; BP: Brain parenchyma; m/Ch: Meningeal membranes and choroid plexus; BBB: Brain blood barrier; Iba1: Ionized calcium-binding adapter molecule 1; bDC: Brain dendritic cells; MHC: Major histocompatibility complex; PRR: Pattern recognition receptor; TLR: Toll-like receptors; LPS: Lipopolysacharides; FC: Flow cytometry; IF: Immunofluorescence; MACS: Magnetic-beads based affinity purification; FBS: Fetal bovine serum; PB: Phosphate buffer; PBS: Phosphate buffer saline; SS: Serum saline; ip: Intraperitoneal; PFA: Paraformaldehyde; DAPI: 4',6-diamino-2-fenilindol; HBSS: Hank's Balanced Sal Solution; DG: Dentate gyrus

\section{Acknowledgements}

We thank Eva Carro (Servicio de Neurología-Neurofisiología Hospital 12 de Octubre, Madrid) for providing APP/PS1 mice. Dr. Fernando GonzálezCamacho for excellent technical assistance in the confocal microscopy, Oscar Zaragoza for technical advice in confocal experimental design, and Raquel Pérez Tavarez for her help with histology methods.

\section{Authors' contributions}

$A F, E Q, P V$, and $B M-J$ performed experiments, contributed substantially to the analysis and interpretation of the data, and reviewed the manuscript. BdA helped with the flow cytometry experiments. BdA, MLG, HM, MV, and IL made substantial contributions to the analysis and interpretation of the data, and critically reviewed the manuscript. EC designed the experimental procedures, made substantial contributions to the analysis and interpretation of the data, drafted and reviewed the manuscript. Project administration and funding by E.C. The authors read and approved the final manuscript.

\section{Funding}

This work was supported by grant from the Spanish Ministry (MINECO) (SAF2016-76451) to E.C and RTI 2018-099114-B-100 to MLG and BdA.

\section{Availability of data and materials}

The datasets generated for this study are available on request to the corresponding author.

\section{Ethics approval and consent to participate}

This study was carried out in accordance with EU and National Animal Care guidelines (directive 2010/63/EU and RD 53/2013). All the procedures were approved by the Institutional Review Board at the ISCIII and the "Consejería de Medio Ambiente del la Comunidad de Madrid" (PROEX179/14).

\section{Consent for publication}

Not applicable

\section{Competing interests}

Authors declare that they have no competing interests.

\section{Author details}

${ }^{1}$ Chronic Disease Programme, Neuroinflammation Unit, Instituto de Salud Carlos III, Carretera Majadahonda-Pozuelo, Km.2,2, Majadahonda, 28220 Madrid, Spain. ${ }^{2}$ Unidad de Inmunobiología, Instituto de Salud Carlos II, Madrid, Spain. ${ }^{3}$ Instituto de Biomedicina de Valencia, Consejo Superior de Investigaciones Científicas, Madrid, Spain.

\section{Received: 3 September 2020 Accepted: 3 February 2021}

Published online: 18 March 2021

References

1. Conde JR, Streit WJ. Microglia in the aging brain. J Neuropathol Exp Neurol. 2006;65(3):199-203.

2. Streit WJ, Sammons NW, Kuhns AJ, Sparks DL. Dystrophic microglia in the aging human brain. Glia. 2004;45(2):208-12.

3. Lee CK, Weindruch R, Prolla TA. Gene-expression profile of the ageing brain in mice. Nat Genet. 2000;25(3):294-7.

4. Lu T, Pan Y, Kao SY, Li C, Kohane I, Chan J, et al. Gene regulation and DNA damage in the ageing human brain. Nature. 2004:429(6994):883-91.

5. Ximerakis M, Lipnick SL, Innes BT, Simmons SK, Adiconis X, Dionne D, et al. Single-cell transcriptomic profiling of the aging mouse brain. Nat Neurosci. 2019;22(10):1696-708.

6. Zhan L, Krabbe G, Du F, Jones I, Reichert MC, Telpoukhovskaia M, et al. Proximal recolonization by self-renewing microglia re-establishes microglial homeostasis in the adult mouse brain. PLoS Biol. 2019;17(2):e3000134.

7. Frank-Cannon TC, Alto LT, McAlpine FE, Tansey MG. Does neuroinflammation fan the flame in neurodegenerative diseases? Mol Neurodegener. 2009;4:47.

8. Ransohoff RM. How neuroinflammation contributes to neurodegeneration. Science. 2016;353(6301):777-83.

9. Hickey WF. Basic principles of immunological surveillance of the normal central nervous system. Glia. 2001;36(2):118-24.

10. Norris GT, Kipnis J. Immune cells and CNS physiology: microglia and beyond. J Exp Med. 2019;216(1):60-70.

11. Khandelwal PJ, Herman AM, Moussa CE. Inflammation in the early stages of neurodegenerative pathology. J Neuroimmunol. 2011;238(1-2):1-11.

12. Prinz M, Priller J, Sisodia SS, Ransohoff RM. Heterogeneity of CNS myeloid cells and their roles in neurodegeneration. Nat Neurosci. 2011;14(10):122735.

13. Ginhoux F, Lim S, Hoeffel G, Low D, Huber T. Origin and differentiation of microglia. Front Cell Neurosci. 2013;7:45

14. Ajami B, Bennett JL, Krieger C, Tetzlaff W, Rossi FM. Local self-renewal can sustain CNS microglia maintenance and function throughout adult life. Nat Neurosci. 2007;10(12):1538-43.

15. Huang $Y, X u$ Z, Xiong S, Sun F, Qin G, Hu G, et al. Repopulated microglia are solely derived from the proliferation of residual microglia after acute depletion. Nat Neurosci. 2018;21(4):530-40.

16. Nimmerjahn A, Kirchhoff F, Helmchen F. Resting microglial cells are highly dynamic surveillants of brain parenchyma in vivo. Science. 2005;308(5726): 1314-8.

17. Olah M, Biber K, Vinet J, Boddeke HW. Microglia phenotype diversity. CNS Neurol Disord Drug Targets. 2011;10(1):108-18.

18. Baron R, Babcock AA, Nemirovsky A, Finsen B, Monsonego A. Accelerated microglial pathology is associated with Abeta plaques in mouse models of Alzheimer's disease. Aging Cell. 2014;13(4):584-95. 
19. Sierra A, Gottfried-Blackmore AC, McEwen BS, Bulloch K. Microglia derived from aging mice exhibit an altered inflammatory profile. Glia. 2007;55(4): 412-24

20. Akiguchi I, Pallas M, Budka H, Akiyama H, Ueno M, Han J, et al. SAMP8 mice as a neuropathological model of accelerated brain aging and dementia: Toshio Takeda's legacy and future directions. Neuropathology. 2017;37(4): 293-305.

21. Morley JE, Farr SA, Kumar VB, Armbrecht HJ. The SAMP8 mouse: a model to develop therapeutic interventions for Alzheimer's disease. Curr Pharm Des. 2012;18(8):1123-30.

22. Perry VH, Nicoll JA, Holmes C. Microglia in neurodegenerative disease. Nat Rev Neurol. 2010;6(4):193-201.

23. Kim YS, Joh TH. Microglia, major player in the brain inflammation: their roles in the pathogenesis of Parkinson's disease. Exp Mol Med. 2006;38(4):333-47.

24. Tao Q, Ang TFA, DeCarli C, Auerbach SH, Devine S, Stein TD, et al. Association of chronic low-grade inflammation with risk of Alzheimer disease in ApoE4 carriers. JAMA Netw Open. 2018;1(6):e183597.

25. Carroll JC, Iba M, Bangasser DA, Valentino RJ, James MJ, Brunden KR, et al. Chronic stress exacerbates tau pathology, neurodegeneration, and cognitive performance through a corticotropin-releasing factor receptor-dependent mechanism in a transgenic mouse model of tauopathy. J Neurosci. 2011; 31(40):14436-49.

26. Tran $\Pi$, Srivareerat M, Alkadhi KA. Chronic psychosocial stress triggers cognitive impairment in a novel at-risk model of Alzheimer's disease. Neurobiol Dis. 2010;37(3):756-63.

27. Gotz J, Bodea LG, Goedert M. Rodent models for Alzheimer disease. Nat Rev Neurosci. 2018;19(10):583-98.

28. Morley JE. The SAMP8 mouse: a model of Alzheimer disease? Biogerontology. 2002;3(1-2):57-60

29. Pallas M, Camins A, Smith MA, Perry G, Lee HG, Casadesus G. From aging to Alzheimer's disease: unveiling "the switch" with the senescence-accelerated mouse model (SAMP8). J Alzheimers Dis. 2008;15(4):615-24.

30. Takeda T. Senescence-accelerated mouse (SAM) with special references to neurodegeneration models, SAMP8 and SAMP10 mice. Neurochem Res. 2009;34(4):639-59.

31. Miyamoto M. Characteristics of age-related behavioral changes in senescence-accelerated mouse SAMP8 and SAMP10. Exp Gerontol. 1997; 32(1-2):139-48.

32. Yagi $H$, Irino $M$, Matsushita $T$, Katoh $S$, Umezawa M, Tsuboyama $T$, et al. Spontaneous spongy degeneration of the brain stem in SAM-P/8 mice, a newly developed memory-deficient strain. J Neuropathol Exp Neurol. 1989; 48(5):577-90.

33. Kawamata T, Akiguchi I, Yagi H, Irino M, Sugiyama H, Akiyama $H$, et al. Neuropathological studies on strains of senescence-accelerated mice (SAM) with age-related deficits in learning and memory. Exp Gerontol. 1997;32(12):161-9.

34. Nomura Y, Okuma Y. Age-related defects in lifespan and learning ability in SAMP8 mice. Neurobiol Aging. 1999;20(2):111-5.

35. Spangler EL, Patel N, Speer D, Hyman M, Hengemihle J, Markowska A, et al. Passive avoidance and complex maze learning in the senescence accelerated mouse (SAM): age and strain comparisons of SAM P8 and R1. J Gerontol A Biol Sci Med Sci. 2002;57(2):B61-8.

36. Diaz-Moreno M, Hortiguela R, Goncalves A, Garcia-Carpio I, Manich G, Garcia-Bermudez E, et al. Abeta increases neural stem cell activity in senescence-accelerated SAMP8 mice. Neurobiol Aging. 2013;34(11):2623-38.

37. Diaz-Moreno M, Armenteros T, Gradari S, Hortiguela R, Garcia-Corzo L, Fontan-Lozano A, et al. Noggin rescues age-related stem cell loss in the brain of senescent mice with neurodegenerative pathology. Proc Natl Acad Sci U S A. 2018;115(45):11625-30.

38. Mrak RE. Microglia in Alzheimer brain: a neuropathological perspective. Int J Alzheimers Dis. 2012;2012:165021

39. Fuster-Matanzo A, Llorens-Martin M, Hernandez F, Avila J. Role of neuroinflammation in adult neurogenesis and Alzheimer disease: therapeutic approaches. Mediators Inflamm. 2013;2013:260925.

40. Bayram B, Nikolai S, Huebbe P, Ozcelik B, Grimm S, Grune T, et al. Biomarkers of oxidative stress, antioxidant defence and inflammation are altered in the senescence-accelerated mouse prone 8. Age (Dordr ). 2013;35(4):1205-17.

41. Grinan-Ferre C, Palomera-Avalos V, Puigoriol-Illamola D, Camins A, Porquet $D$, Pla $V$, et al. Behaviour and cognitive changes correlated with hippocampal neuroinflammaging and neuronal markers in female SAMP8, a model of accelerated senescence. Exp Gerontol. 2016;80:57-69.
42. Tha KK, Okuma Y, Miyazaki H, Murayama T, Uehara T, Hatakeyama R, et al. Changes in expressions of proinflammatory cytokines IL-1beta, TNF-alpha and IL-6 in the brain of senescence accelerated mouse (SAM) P8. Brain Res. 2000;885(1):25-31.

43. Shaftel SS, Griffin WS, O'Banion MK. The role of interleukin-1 in neuroinflammation and Alzheimer disease: an evolving perspective. J Neuroinflammation. 2008;5:7

44. Ye SM, Johnson RW. Increased interleukin- 6 expression by microglia from brain of aged mice. J Neuroimmunol. 1999;93(1-2):139-48.

45. Heppner FL, Ransohoff RM, Becher B. Immune attack: the role of inflammation in Alzheimer disease. Nat Rev Neurosci. 2015;16(6):358-72.

46. Niraula A, Sheridan JF, Godbout JP. Microglia priming with aging and stress. Neuropsychopharmacology. 2017;42(1):318-33.

47. Perry VH, Teeling J. Microglia and macrophages of the central nervous system: the contribution of microglia priming and systemic inflammation to chronic neurodegeneration. Semin Immunopathol. 2013;35(5):601-12.

48. Neher JJ, Cunningham C. Priming microglia for innate immune memory in the brain. Trends Immunol. 2019;40(4):358-74.

49. Olson JK, Miller SD. Microglia initiate central nervous system innate and adaptive immune responses through multiple TLRs. J Immunol. 2004;173(6): 3916-24.

50. Wang J, Zhao D, Pan B, Fu Y, Shi F, Kouadir M, et al. Toll-like receptor 2 deficiency shifts PrP106-126-induced microglial activation from a neurotoxic to a neuroprotective phenotype. J Mol Neurosci. 2015;55(4):880-90.

51. Cunningham C, Campion S, Lunnon K, Murray CL, Woods JF, Deacon RM, et al. Systemic inflammation induces acute behavioral and cognitive changes and accelerates neurodegenerative disease. Biol Psychiatry. 2009; 65(4):304-12.

52. Morris MC, Gilliam EA, Button J, Li L. Dynamic modulation of innate immune response by varying dosages of lipopolysaccharide (LPS) in human monocytic cells. J Biol Chem. 2014;289(31):21584-90.

53. Bartolome F, de la Cueva M, Pascual C, Antequera D, Fernandez T, Gil C, et al. Amyloid beta-induced impairments on mitochondrial dynamics, hippocampal neurogenesis, and memory are restored by phosphodiesterase 7 inhibition. Alzheimers Res Ther. 2018;10(1):24.

54. Paxinos G, Franklin K. Mouse brain in stereotaxic coordinates. 5th edición. Academic Press. Elsevier; 2012. ISBN: 9780128161593.

55. Quintana E, Fernandez A, Velasco P, de Andrés B, Liste I, Sancho D, et al. DNGR-1(+) dendritic cells are located in meningeal membrane and choroid plexus of the noninjured brain. Glia. 2015;63(12):2231-48.

56. Catalin B, Mitran S, Albu C, lancau M. Comparative aspects of microglia reaction in white and gray matter. Curr Health Sci J. 2013:39(3):151-4.

57. Ferreira T, Ou Y, Li S, Giniger E, van Meyel DJ. Dendrite architecture organized by transcriptional control of the F-actin nucleator Spire. Development. 2014;141(3):650-60.

58. Ristanovic D, Milosevic NT, Stulic V. Application of modified Sholl analysis to neuronal dendritic arborization of the cat spinal cord. J Neurosci Methods. 2006;158(2):212-8

59. Carson MJ, Reilly CR, Sutcliffe JG, Lo D. Mature microglia resemble immature antigen-presenting cells. Glia. 1998;22(1):72-85.

60. Livak KJ, Schmittgen TD. Analysis of relative gene expression data using real-time quantitative PCR and the 2(-Delta Delta C(T)) Method. Methods. 2001;25(4):402-8.

61. Auge E, Cabezon I, Pelegri C, Vilaplana J. New perspectives on corpora amylacea in the human brain. Sci Rep. 2017;7:41807.

62. Akiyama H, Kameyama M, Akiguchi I, Sugiyama H, Kawamata T, Fukuyama $\mathrm{H}$, et al. Periodic acid-Schiff (PAS)-positive, granular structures increase in the brain of senescence accelerated mouse (SAM). Acta Neuropathol. 1986; 72(2):124-9.

63. Manich G, Cabezon I, Auge E, Pelegri C, Vilaplana J. Periodic acid-Schiff granules in the brain of aged mice: from amyloid aggregates to degenerative structures containing neo-epitopes. Ageing Res Rev. 2016;27: 42-55.

64. Nakamura S, Akiguchi I, Seriu N, Ohnishi K, Takemura M, Ueno M, et al. Monoamine oxidase-B-positive granular structures in the hippocampus of aged senescenceaccelerated mouse (SAMP8). Acta Neuropathol. 1995;90(6):626-32.

65. Schoenen J. The dendritic organization of the human spinal cord: the dorsal horn. Neuroscience. 1982;7(9):2057-87.

66. Garcia-Segura LM, Perez-Marquez J. A new mathematical function to evaluate neuronal morphology using the Sholl analysis. J Neurosci Methods. 2014;226:103-9. 
67. Tremblay ME, Zettel ML, Ison JR, Allen PD, Majewska AK. Effects of aging and sensory loss on glial cells in mouse visual and auditory cortices. Glia. 2012;60(4):541-58.

68. Hasegawa-Ishii S, Takei S, Chiba Y, Furukawa A, Umegaki H, Iguchi A, et al. Morphological impairments in microglia precede age-related neuronal degeneration in senescence-accelerated mice. Neuropathology. 2011:31(1):20-8.

69. Paasila PJ, Davies DS, Kril JJ, Goldsbury C, Sutherland GT. The relationship between the morphological subtypes of microglia and Alzheimer's disease neuropathology. Brain Pathol. 2019;29(6):726-40.

70. Mah LJ, El-Osta A, Karagiannis TC. GammaH2AX as a molecular marker of aging and disease. Epigenetics. 2010;5(2):129-36.

71. Pospelova TV, Demidenko ZN, Bukreeva El, Pospelov VA, Gudkov AV, Blagosklonny MV. Pseudo-DNA damage response in senescent cells. Cell Cycle. 2009;8(24):4112-8.

72. Barral S, Beltramo R, Salio C, Aimar P, Lossi L, Merighi A. Phosphorylation of histone $\mathrm{H} 2 \mathrm{AX}$ in the mouse brain from development to senescence. Int J Mol Sci. 2014;15(1):1554-73.

73. Myung NH, Zhu X, Kruman II, Castellani RJ, Petersen RB, Siedlak SL, et al. Evidence of DNA damage in Alzheimer disease: phosphorylation of histone H2AX in astrocytes. Age (Dordr ). 2008;30(4):209-15.

74. Shanbhag NM, Evans MD, Mao W, Nana AL, Seeley WW, Adame A, et al. Early neuronal accumulation of DNA double strand breaks in Alzheimer's disease. Acta Neuropathol Commun. 2019;7(1):77.

75. Simpson JE, Ince PG, Haynes L, Theaker R, Gelsthorpe C, Baxter L, et al. Population variation in oxidative stress and astrocyte DNA damage in relation to Alzheimer-type pathology in the ageing brain. Neuropathol Appl Neurobiol. 2010;36(1):25-40.

76. Wyss-Coray T, Mucke L. Inflammation in neurodegenerative disease--a double-edged sword. Neuron. 2002;35(3):419-32.

77. Hart AD, Wyttenbach A, Perry VH, Teeling JL. Age related changes in microglial phenotype vary between CNS regions: grey versus white matter differences. Brain Behav Immun. 2012;26(5):754-65.

78. Kawamata T, Akiguchi I, Maeda K, Tanaka C, Higuchi K, Hosokawa M, et al. Agerelated changes in the brains of senescence-accelerated mice (SAM): association with glial and endothelial reactions. Microsc Res Tech. 1998;43(1):59-67.

79. Jung S, Aliberti J, Graemmel P, Sunshine M, Kreutzberg GW, Sher A, et al. Analysis of fractalkine receptor $\mathrm{CX}(3) \mathrm{CR} 1$ function by targeted deletion and green fluorescent protein reporter gene insertion. Mol Cell Biol. 2000;20(11):4106-14.

80. Ransohoff RM, Engelhardt B. The anatomical and cellular basis of immune surveillance in the central nervous system. Nat Rev Immunol. 2012;12(9):623-35.

81. Baron JL, Madri JA, Ruddle NH, Hashim G, Janeway CA Jr. Surface expression of alpha 4 integrin by CD4 T cells is required for their entry into brain parenchyma. J Exp Med. 1993;177(1):57-68.

82. Wohleb ES, McKim DB, Sheridan JF, Godbout JP. Monocyte trafficking to the brain with stress and inflammation: a novel axis of immune-to-brain communication that influences mood and behavior. Front Neurosci. 2014;8:447.

83. Bowman RL, Klemm F, Akkari L, Pyonteck SM, Sevenich L, Quail DF, et al. Macrophage ontogeny underlies differences in tumor-specific education in brain malignancies. Cell Rep. 2016;17(9):2445-59.

84. Lucin KM, Wyss-Coray T. Immune activation in brain aging and neurodegeneration: too much or too little? Neuron. 2009;64(1):110-22.

85. Chen Z, Jalabi W, Shpargel KB, Farabaugh KT, Dutta R, Yin X, et al. Lipopolysaccharide-induced microglial activation and neuroprotection against experimental brain injury is independent of hematogenous TLR4. J Neurosci. 2012;32(34):11706-15.

86. Furube E, Kawai S, Inagaki H, Takagi S, Miyata S. Brain region-dependent heterogeneity and dose-dependent difference in transient microglia population increase during lipopolysaccharide-induced inflammation. Sci Rep. 2018;8(1):2203.

87. Perry VH, Newman TA, Cunningham C. The impact of systemic infection on the progression of neurodegenerative disease. Nat Rev Neurosci. 2003;4(2):103-12.

88. Wolozin B. Regulated protein aggregation: stress granules and neurodegeneration. Mol Neurodegener. 2012;7:56.

89. Mouton PR, Long JM, Lei DL, Howard V, Jucker M, Calhoun ME, et al. Age and gender effects on microglia and astrocyte numbers in brains of mice. Brain Res. 2002;956(1):30-5.

90. Adachi M, Abe M, Sasaki T, Kato H, Kasahara J, Araki T. Role of inducible or neuronal nitric oxide synthase in neurogenesis of the dentate gyrus in aged mice. Metab Brain Dis. 2010;25(4):419-24.

91. Hayakawa N, Kato H, Araki T. Age-related changes of astorocytes, oligodendrocytes and microglia in the mouse hippocampal CA1 sector. Mech Ageing Dev. 2007;128(4):311-6.
92. Vanguilder HD, Bixler GV, Brucklacher RM, Farley JA, Yan H, Warrington JP, et al. Concurrent hippocampal induction of MHC II pathway components and glial activation with advanced aging is not correlated with cognitive impairment. J Neuroinflammation. 2011:8:138.

93. Liu J, Wang MW, Gu P, Ma QY, Wang YY, Geng Y, et al. Microglial activation and age-related dopaminergic neurodegeneration in MPTP-treated SAMP8 mice. Brain Res. 2010;1345:213-20.

94. Matyszak MK, Denis-Donini S, Citterio S, Longhi R, Granucci F, Ricciardi-Castagnoli P. Microglia induce myelin basic protein-specific T cell anergy or T cell activation, according to their state of activation. Eur J Immunol. 1999;29(10):3063-76.

95. Frank MG, Barrientos RM, Biedenkapp JC, Rudy JW, Watkins LR, Maier SF. mRNA up-regulation of MHC II and pivotal pro-inflammatory genes in normal brain aging. Neurobiol Aging. 2006;27(5):717-22.

96. Frank MG, Barrientos RM, Watkins LR, Maier SF. Aging sensitizes rapidly isolated hippocampal microglia to LPS ex vivo. J Neuroimmunol. 2010; 226(1-2):181-4.

97. Perry VH, Matyszak MK, Fearn S. Altered antigen expression of microglia in the aged rodent CNS. Glia. 1993;7(1):60-7.

98. Shimada A, Hasegawa-Ishii S. Senescence-accelerated mice (SAMs) as a model for brain aging and immunosenescence. Aging Dis. 2011;2(5):414-35.

99. Erickson MA, Banks WA. Age-associated changes in the immune system and blood brain barrier functions. Int J Mol Sci. 2019;20(7):1632-59.

100. Lee JK, Tansey MG. Microglia isolation from adult mouse brain. Methods Mol Biol. 2013;1041:17-23.

101. Sedgwick JD, Schwender S, Imrich H, Dorries R, Butcher GW, ter Meulen V. Isolation and direct characterization of resident microglial cells from the normal and inflamed central nervous system. Proc Natl Acad Sci U S A. 1991;88(16):7438-42.

102. Legroux L, Pittet CL, Beauseigle D, Deblois G, Prat A, Arbour N. An optimized method to process mouse CNS to simultaneously analyze neural cells and leukocytes by flow cytometry. J Neurosci Methods. 2015;247:23-31.

103. Posel C, Moller K, Boltze J, Wagner DC, Weise G. Isolation and flow cytometric analysis of immune cells from the ischemic mouse brain. J Vis Exp. 2016;108:53658.

104. Singh V, Mitra S, Sharma AK, Gera R, Ghosh D. Isolation and characterization of microglia from adult mouse brain: selected applications for ex vivo evaluation of immunotoxicological alterations following in vivo xenobiotic exposure. Chem Res Toxicol. 2014;27(5):895-903.

105. Cardona AE, Huang D, Sasse ME, Ransohoff RM. Isolation of murine microglial cells for RNA analysis or flow cytometry. Nat Protoc. 2006;1 (4):1947-51.

106. Pelegri C, Canudas AM, del Valle J, Casadesus G, Smith MA, Camins A, et al. Increased permeability of blood-brain barrier on the hippocampus of a murine model of senescence. Mech Ageing Dev. 2007;128(9):522-8.

107. Ueno M, Sakamoto H, Kanenishi K, Onodera M, Akiguchi I, Hosokawa M. Ultrastructural and permeability features of microvessels in the periventricular area of senescence-accelerated mice (SAM). Microsc Res Tech. 2001;53(3):232-8.

108. Banks WA, Farr SA, Morley JE. Permeability of the blood-brain barrier to albumin and insulin in the young and aged SAMP8 mouse. J Gerontol A Biol Sci Med Sci. 2000;55(12):B601-6.

109. Perry VH, Cunningham $\mathrm{C}$, Holmes C. Systemic infections and inflammation affect chronic neurodegeneration. Nat Rev Immunol. 2007;7(2):161-7.

110. Perry VH. Contribution of systemic inflammation to chronic neurodegeneration. Acta Neuropathol. 2010;120(3):277-86.

111. Proescholdt MG, Chakravarty S, Foster JA, Foti SB, Briley EM, Herkenham M. Intracerebroventricular but not intravenous interleukin-1 beta induces widespread vascular-mediated leukocyte infiltration and immune signal mRNA expression followed by brain-wide glial activation. Neuroscience. 2002;112(3):731-49.

112. Depino A, Ferrari C, Pott Godoy MC, Tarelli R, Pitossi FJ. Differential effects of interleukin-1 beta on neurotoxicity, cytokine induction and glial reaction in specific brain regions. J Neuroimmunol. 2005;168(1-2):96-110.

113. Hasegawa-Ishii S, Inaba M, Shimada A. Widespread time-dependent changes in tissue cytokine concentrations in brain regions during the acute phase of endotoxemia in mice. Neurotoxicology. 2020;76:67-74.

\section{Publisher's Note}

Springer Nature remains neutral with regard to jurisdictional claims in published maps and institutional affiliations. 